\title{
Therapeutic potential of thalidomide for gemcitabine-resistant bladder cancer
}

\author{
YEN TA HUANG ${ }^{1,2}$, CHUAN CHU CHENG $^{3}$, TED H. CHIU ${ }^{5}$ and PEI CHUN LAI ${ }^{1,4}$ \\ ${ }^{1}$ Department of Medicine, Tzu Chi University; ${ }^{2}$ Surgical Intensive Care Unit, \\ Departments of ${ }^{3}$ Medical Research and ${ }^{4}$ Pediatrics, Buddhist Tzu Chi General Hospital; \\ ${ }^{5}$ Department of Pharmacology, College of Medicine, Tzu Chi University, Hualien, Taiwan, R.O.C.
}

Received June 11, 2015; Accepted July 23, 2015

DOI: 10.3892/ijo.2015.3155

\begin{abstract}
Controversial effects of thalidomide for solid malignancies have been reported. In the present study, we evaluate the effects of thalidomide for transitional cell carcnoma (TCC), the most common type of bladder cancer. Thalidomide precipitates were observed when its DMSO solution was added to the culture medium. No precipitation was found when thalidomide was dissolved in $45 \% \gamma$-cyclodextrin, and this concentration of $\gamma$-cyclodextrin elicited slight cytotoxicity on TCC BFTC905 and primary human urothelial cells. Thalidomide- $\gamma$-cyclodextrin complex exerted a concentrationdependent cytotoxicity in TCC cells, but was relatively less cytotoxic (with $\mathrm{IC}_{50}$ of $200 \mu \mathrm{M}$ ) in BFTC905 cells than the other 3 TCC cell lines, possibly due to upregulation of Bcl-xL and HIF- $1 \alpha$ mediated carbonic anhydrase IX, and promotion of quiescence. Gemcitabine-resistant BFTC905 cells were chosen for additional experiments. Thalidomide induced apoptosis through downregulation of survivin and securin. The secretion of VEGF and TNF- $\alpha$ was ameliorated by thalidomide, but they did not affect cell proliferation. Immune-modulating lenalidomide and pomalidomide did not elicit cytotoxicity. In addition, cereblon did not play a role in the thalidomide effect. Oxidative DNA damage was triggered by thalidomide, and anti-oxidants reversed the effect. Thalidomide also inhibited TNF- $\alpha$ induced invasion through inhibition of NF- $\mathrm{KB}$, and downregulation of effectors, ICAM-1 and MMP-9. Thalidomide inhibited the growth of BFTC905 xenograft tumors in SCID mice via induction of DNA damage and suppression of angiogenesis. Higher average body weight, indicating less chachexia, was observed in thalidomide treated group. Sedative effect was observed within one-week of treatment. These pre-clinical results suggest therapeutic potential of thalidomide for gemcitabine-resistant bladder cancer.
\end{abstract}

Correspondence to: Dr Pei Chun Lai, Department of Pediatrics, Buddhist Tzu Chi General Hospital, 707, Section 3, Chung Yang Road, Hualien 970, Taiwan, R.O.C.

E-mail: chunta.lab@gmail.com

Key words: thalidomide, bladder cancer, transitional cell carcinoma

\section{Introduction}

Bladder cancer is still one of the most common malignancies in the world (1). Pathologically, $>90 \%$ of bladder cancer is transitional cell carcinoma (TCC) (2). Surgery, radiation, and chemotherapy are evidence-based treatments depending on clinical staging $(3,4)$. Chemotherapy with standard regimen MVAC (methotrexate, vinblastine, adriamycin, and cisplatin) or more tolerable regimen GC (gemcitabine and cisplatin) for advanced or metastatic bladder cancer has shown poor response (5). However, once diagnosed as a muscle-invasive type, the 5-year survival and freedom from relapse rate under conservative multimodality therapies were 54 and $42 \%$, respectively (6). Therefore, we need to investigate new strategies for bladder cancer treatment.

Thalidomide possesses anti-angiogenic and immunomodulatory effects (7). It has been widely used for the standard therapies of multiple myeloma (MM) (8), based not only on its anti-angiogenic and immunomodulatory mechanisms but also on inducing apoptosis (9). Its new analogues, so called IMiDs (immunomodulatory drugs), lenalidomide and pomalidomide, have also been approved by US FDA for MM therapy with satisfactory and tolerable responses (10-12). Thalidomide has also been used clinically for the treatments of some solid tumors, such as hepatocellular carcinoma $(13,14)$ and glioblastoma multiforme $(15,16)$, but controversial effects were observed in these studies. Beyond its well-known anti-angiogenic property, only few studies of cytotoxic effect (17) and migratory inhibition (18) on solid tumor cells have been reported. In the present study, we demonstrated the therapeutic effects of thalidomide via induction of intracellular reactive oxygen species (ROS) to elicit apoptosis, inhibition of angiogenesis, and suppression of invasion in gemcitabine-resistant TCC BFTC905 cells in vitro and in vivo.

\section{Materials and methods}

Cell lines and cell culture. Four TCC cell lines were used: BFTC905 (19), BFTC909 (19), T24, and TSGH8301. Cells were maintained as described previously $(20,21)$. BFTC 905 cells were gemcitabine-resistant (22). We also used primary human urothelial cells (HUCs) (ScienCell Research Laboratories, Carlsbad, CA, USA) (22). 
MTT cytotoxicity assay. Procedures as previously described were followed $(21,23)$. Thalidomide (Sigma-Aldrich, St. Louis, MO, USA), gemcitabine (Sigma-Aldrich), pomalidomide (kindly provided by Professor Chinpiao Chen, Department of Chemistry, National Don Hwa University, Hualien, Taiwan), lenalidomide (LC Laboratories, Woburn, MA, USA), CRBN siRNA/scrambled siRNA (Santa Cruz Biotechnology, Santa Cruz, CA, USA), N-acetylcysteine (NAC, Sigma-Aldrich), and dl-dithiothreitol (DTT, Sigma-Aldrich) were used in individual experiments. Gemcitabine, NAC, and DTT were dissolved in distilled water. Dimethyl sulfoxide (DMSO, J.T. Baker, Phillipsburg, NJ, USA), (2-hydroxypropyl)- $\beta$-cyclodextrin (Sigma-Aldrich), $\gamma$-cyclodextrin (Sigma-Aldrich), carboxymethyl cellulose (CMC, Sigma-Aldrich), and Cremophor-EL (Sigma-Aldrich) were chosen as the solvent to dissolve thalidomide, and the viability changes after administration of these solvents were tested. The protocol for siRNA transfection provided by Santa Cruz Biotechnology was followed. The cell viability was calculated according to the following formula: cell viability $=$ (absorbance of the experimental group) $/$ (absorbance of reference group) x 100\%. Reference group was administered with equal volume of PBS (phosphate-buffered saline) as control.

Cell proliferation by trypan blue exclusion test. For cell proliferation assay, thalidomide at $0-200 \mu \mathrm{M}$ was administered (day 1) after overnight seeding of $1 \times 10^{4}$ BFTC905 cells in $10-\mathrm{cm}$ dish with complete medium. Subsequently, the cells were re-cultured with fresh medium and administration of each concentration of thalidomide on day 5. Administration of equal volume of vehicle $\gamma$-cyclodextrin was used as control. Viable cells do not take up impermeable trypan blue (24), so counts of cells with negative stainings of trypan blue (Sigma-Aldrich) were calculated by a hemocytometer on days 5 and 9 . In another experiment, thalidomide at $200 \mu \mathrm{M}$ plus $100 \mathrm{nM}$ recombinant human vascular endothelial growth factor (VEGF, PreproTech, Rocky Hill, NJ, USA), $100 \mathrm{nM}$ human recombinant basic fibroblast grow th factor (bFGF, Merck Millipore, Darmstadt, Germany), or 100 ng/ml human recombinant tumor necrosis factor- $\alpha$ (TNF- $\alpha$, Merck Millipore) were administered after overnight seeding of $1 \times 10^{4}$ BFTC905 cells in 10-cm dish (day 1). Administration of equal volume of PBS was used as control. Trypan bluenegative cells were calculated on day 3 . To determine the appropriate concentration of TNF- $\alpha$ for experiment of invasion without the proliferative effects, a 48-h administration of TNF- $\alpha$ at $0-100 \mathrm{ng} / \mathrm{ml}$ on BFTC905 cells was cultured in the medium with $1 \%$ FBS. Then trypan blue-negative cells were counted.

Western blotting. Conventional protocols as described previously were followed (20). Primary antibodies were purchased from the following vendors: Cell Signaling Technology (Danvers, MA, USA), anti-survivin (no. 2808), anti-LC3B (no. 2775), cell cycle regulation (no. 9932), and cell cycle/checkpoint antibody sampler kits (no. 9917); Abcam (Cambridge, MA, USA), anti-securin (ab3305) and anti-cleaved PARP [poly (ADP-ribose) polymerase, ab4830]; R\&D Systems (Minneapolis, MN, USA), anti-CAIX (carbonic anhydrase 9, AF 2188); GeneTex (Irvine, CA, USA), anti-
HIF-1 $\alpha$ (hypoxia-inducible factor 1 alpha, GTX 127309), anti-caspase 3 (GTX110543), anti-Bcl2 (B-cell lymphoma 2, GTX127958), anti-Bax (Bcl-2-associated X protein, GTX109683), anti-cIAP1 (cellular inhibitor of apoptosis 1, GTX110087), anti-cIAP2 (GTX113128), anti-Bcl-xL (B-cell lymphoma-extra-large, GTX105661), anti-TCTP (translationally controlled tumor protein, GTX63597), anti-cyclin A1 (GXT103042), anti-cyclin B1 (GTX100911), anti-cyclin D1 (GTX112874), anti-cyclin E1 (GTX103045), and anti-cereblon (GTX 45011); and Santa Cruz Biotechnology (Dallas, TX, USA), anti-Ki-67 (sc-15402), anti-MMP-9 (matrix metalloproteinase 9, sc-6840), anti-ICAM-1 (intercellular adhesion molecule 1, sc-7891), anti-CD34 (sc-9095), $\alpha$-tubulin (sc-8305), and actin (sc-1616). Expression of $\alpha$-tubulin or actin was used as the internal standard.

Cell cycle analysis. After treatment, the supernatant and the dead BFTC905 cells were removed. Only the cell cycle changes in the viable BFTC905 cells were analyzed. Procedures using flow cytometry (Bedford, MA, USA), as described, were followed (22).

DNA damage assay. The Cell Death Detection ELISA ${ }^{\text {plus }}$ (Roche, Mannheim, Germany) assay kit was used to differentiate apoptotic or necrotic condition of BFTC905 cells after thalidomide treatment. Procedures as previously described were followed (25). To determine the oxidative DNA damage, OxiSelect $^{\mathrm{TM}}$ Oxidative DNA Damage ELISA kit (Cell Biolabs, San Diego, CA, USA) was used for the detection and quantitation of 8-hydroxy-2'-deoxyguanosine (8-OHdG).

Immunofluorescent stainings of DCF (2',7' dichlorodihydrofluorescein). The procedures using OxiSelect ${ }^{\mathrm{TM}}$ Intracellular ROS (reactive oxygen species) Assay kit (Cell Biolabs) were followed. The intensity of greenish fluorescence of DCF is proportional to the levels of ROS production in the cytoplasm of BFTC905 cells. The cells were photographed (x100) $48 \mathrm{~h}$ after exposure to IMiDs or vehicle.

Total oxidant status (TOS) assay. TOS levels were measured by commercial assay kit (Rel Assay Diagnostics, Turkey) (26). The oxidants in BFTC905 cells oxidized the ferrous ion-chelator complex to ferric ion. The oxidation reaction was prolonged by the enhanced molecule, glycerol, which was abundant in the reaction medium. The ferric ion produced a colored complex with xylenol orange in an acidic medium. The color intensity, measured as OD (optic density) at $530 \mathrm{~nm}$ by a spectrophotometer, was recorded at $6,12,24,48 \mathrm{~h}$ after BFTC905 cells were treated with $200 \mu \mathrm{M}$ thalidomide or vehicle. Due to significant differences of cell counts between vehicle and thalidomide treatment, the changes of TOS at each time-point were calculated according to the following formula: TOS ratio per cell $=[(\mathrm{OD}$ value of thalidomide treatment $) /$ (cell counts of thalidomide treatment $)] \div[(\mathrm{OD}$ value of vehicle treatment $) /($ cell counts of vehicle treatment)]. Cell counts were calculated conventionally by a hemocytometer.

Matrigel invasion assay. The BioCoat ${ }^{\mathrm{TM}}$ growth factor reduced Matrigel ${ }^{\mathrm{TM}}$ Invasion Chamber (BD Biosciences) was used for in vitro invasion study. TNF- $\alpha$ at $10 \mathrm{ng} / \mathrm{ml}$ and/or 
$50 \mu \mathrm{M}$ of thalidomide were added to the chamber with medium containing $1 \%$ FBS. Subsequently, the chambers were put into $24-w e l l$ plate containing medium plus $10 \% \mathrm{FBS}$ for $24 \mathrm{~h}$. The protocol as described previously was followed (23). BFTC905 cells attached on the bottom layer of chambers were counted from 10 randomized fields (x200).

Immunocytochemistry. The protocol as described previously was followed (20). Primary antibody of anti-NF- $\kappa \mathrm{B}$ (nuclear factor kappa-light-chain-enhancer of activated B cells) p65 (SC-109, Santa Cruz Biotechnology) was used. After 48-h treatment with thalidomide or vehicle with/without TNF- $\alpha$ stimulation, BFTC905 cells fixed on the slides with positive immunostaining for nuclear NF- $\mathrm{B}$ p 65 were counted from 5 randomized fields (x200).

Enzyme-linked immunosorbent assay (ELISA). Human BDNF (brain-derived neurotrophic factor) Quantikine ${ }^{\mathrm{TM}}$ ELISA kit purchased from R\&D Systems and human VEGF (vascular endothelial growth factor), as well as bFGF (basic fibroblast growth factor) and TNF- $\alpha$ ELISA kit purchased from Millipore were used to detect the above molecules in culture medium. The procedures were recommended by the manufacturer and used in our previous study (20). MMP-9 activity in culture medium was also measured by ELISA method (Biotrak activity assay system, Amersham Pharmacia Biotech, Little Chalfont, UK). After 48-h treatment with thalidomide or vehicle with/without TNF- $\alpha$ stimulation, MMP-9 activity in the medium was assayed according to the manufacturer's instructions.

Mouse xenograft model. BFTC905 xenograft model and protocol in NOD.CB17-Prkdc ${ }^{\text {scid}} /$ Tcu (SCID) male mice were established in our previous study (20). BFCT905 cells $\left(1 \times 10^{6}\right)$ were implanted s.c. into the right inguinal area of SCID mice, concomitantly $250 \mathrm{mg} / \mathrm{kg}$ of thalidomide or vehicle was administered s.c. into the loading site of cancer cells when the tumor was impalpable or directly into the tumor 3 times per week $(\mathrm{W} 1,3,5)$ since the day of implantation. In another experiment to evaluate the therapeutic effects, the same dosage of thalidomide with the same frequency was administered for 2 weeks after implantation of BFTC905 cells for 3 weeks. Body weight was measured after sacrifice, and necropsy of xenografts was performed immediately. Tumor volumes were calculated using the formula: [1/2] $\mathrm{x} \mathrm{a} \mathrm{x} \mathrm{b}^{2}$, where $\mathrm{a}$ and $\mathrm{b}$ represent the largest and smallest tumor diameters, respectively. Expression of cleaved PARP and CD34 was determined by western blotting, and expression of human VEGF was measured by ELISA.

Locomotor activity. Locomotor activity as described were followed (27). Briefly, a 30-min habituation period was used prior to the first episode of administration of thalidomide or vehicle. Images of traveled distance, the so-called locomotor activity, were captured by a video camera and the recorded images were analyzed by TrackMot software (Diagnostic \& Research Instruments Co., Taoyuan, Taiwan). The activity was summated consecutively for two 10-min intervals following the drug injection. All animals without xenograft implantation were used only once with 3 drug injections (W1, 3, 5).
Statistical analysis. Data were analyzed by Student's t-test, Mann-Whitney U test, or one-way/two-way ANOVA based on individual data, and presented as mean \pm SEM (standard error of mean). In all cases, $\mathrm{p}<0.05$ was considered statistically significant, and indicated in the figures as: ${ }^{*} 0.01 \leq \mathrm{p}<0.05$, ${ }^{* *} 0.005 \leq \mathrm{p}<0.01$ and ${ }^{* * *} \mathrm{p}<0.005$, respectively.

\section{Results}

Only the $\gamma$-cyclodextrin did not elicit cytotoxicity in BFTC905 cells. Based on the literature, initially we used DMSO as the solvent for thalidomide (Fig. 1A). However, precipitation of thalidomide was observed immediately following addition of thalidomide-DMSO solution into culture medium (Fig. 1B). Therefore, several solvents or substances were tested for their ability to carry thalidomide into culture medium without precipitation. We observed that cremophorEL, (2-hydroxypropyl)- $\beta$-cyclodextrin and $\gamma$-cyclodextrin can dissolve thalidomide, while carboxymethyl cellulose (CMC) can keep thalidomide in a suspension state. To test the cytotoxicity of these solvents, BFTC905 cells were exposed to different $\mathrm{v} / \mathrm{v}$ ratios of solvent/culture medium $(0-1 \%)$ for $48 \mathrm{~h}$. At $1 \%$ of $\mathrm{v} / \mathrm{v}$, only $45 \% \gamma$-cyclodextrin did not exert cytotoxicity in BFTC905 cells ( $\mathrm{p}=0.198, \mathrm{n}=3$; Fig. 2A). Whereas, $\gamma$-cyclodextrin did not elicit significant cytotoxicity in primary HUC cells, except at the concentration of $1 \% \mathrm{v} / \mathrm{v}$ ( $\mathrm{p}=0.002$, n=3; Fig. 2B). No precipitation was observed when thalidomide $/ 45 \% \gamma$-cyclodextrin solution was added into the culture medium (Fig. 2C). Thalidomide dissolved in $45 \%$ $\gamma$-cyclodextrin was used for the subsequent experiments.

Cytotoxicity of thalidomide on TCC and primary human urothelial cells. After 48-h treatment, thalidomide (dissolved in $45 \% \gamma$-cyclodextrin) caused a concentration-dependent cytotoxicity on TCC cells $(\mathrm{p}<0.05$ in all TCC cell lines by one-way ANOVA, n=3; Fig. 3A). Thalidomide exerted significant less cytotoxic effect in BFTC905 cells compared to other TCC cell lines (all $\mathrm{p}<0.05$ by two-way ANOVA). The viability of BFTC 905 cells after administration of thalidomide dissolved in $\gamma$-cyclodextrin appeared to plateau at $200 \mu \mathrm{M}(51.0 \pm 7.0 \%$ vs. $47.1 \pm 7.1 \%$ for 200 and $500 \mu \mathrm{M}$, respectively; $\mathrm{p}=0.714)$. The $\mathrm{v} / \mathrm{v}$ of thalidomide and $45 \%$ $\gamma$-cyclodextrin mixture at 200 and $500 \mu \mathrm{M}$ was 0.4 and $0.8 \%$, respectively. The viability of HUCs was not altered after administration of $200 \mu \mathrm{M}$ thalidomide dissolved in $45 \%$ $\gamma$-cyclodextrin $(\mathrm{p}=0.2, \mathrm{n}=3)$, but $500 \mu \mathrm{M}$ thalidomide elicited significant cytotoxicity in HUC cells $(\mathrm{p}=0.006)$. Therefore, $200 \mu \mathrm{M}$ thalidomide dissolved in $45 \% \gamma$-cyclodextrin was used for the subsequent experiments.

Furthermore, we examined the cytotoxicity of gemcitabine, the main current therapy for bladder cancer plus thalidomide on TCC cells (Fig. 3B). After 48-h treatment, the viability of BFTC905, BFTC909, and TSGH8301 cells was similar between thalidomide alone $(200 \mu \mathrm{M})$ and thalidomide plus gemcitabine $(100 \mathrm{nM})$ group. Significant additive cytotoxicity for the combination of gemcitabine and thalidomide was only observed in T24 cells $(37.6 \pm 3.4$ vs. $18.7 \pm 5.0 \%$ for thalidomide alone vs. thalidomide plus gemcitabine treatment, respectively; $\mathrm{p}=0.03, \mathrm{n}=3$ ). Therefore, gemcitabine-resistant TCC cell line BFTC905 (22) was 
A

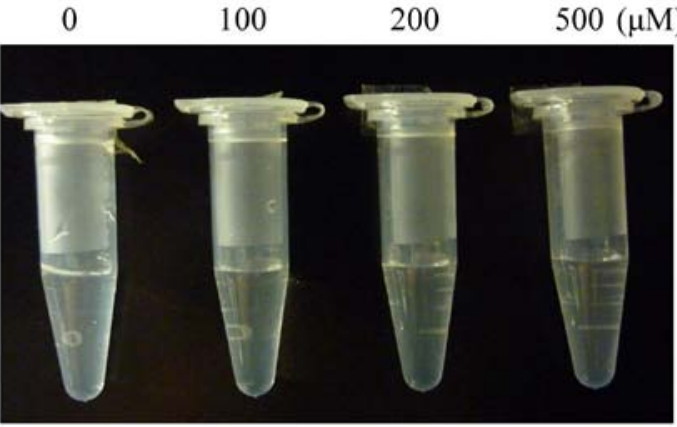

B

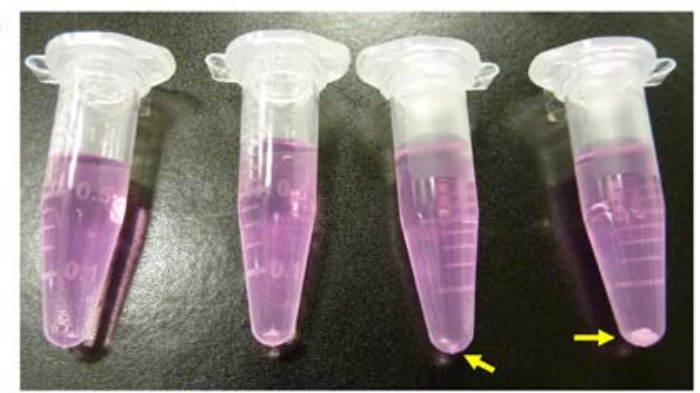

Figure 1. The precipitation of thalidomide. (A) Clear solutions of thalidomide $\leq 500 \mu \mathrm{M}$ dissolved in DMSO. (B) Precipitates (yellow arrow) of thalidomide dissolved in DMSO settled to the bottom of Eppendorf tube when mixed with culture medium.

chosen to investigate the therapeutic effects of thalidomide in $45 \% \gamma$-cyclodextrin in the following experiments.

Autophagy mediated survival of cancer cells by overcoming hypoxia and a shortage of nutrients (28). To delineate why thalidomide elicited less efficacy on BFTC905 cells, the expression of LC3B-II, HIF-1 $\alpha$, and CAIX was determined after thalidomide treatment. Expression of LC3B-II, a marker of autophagy and converted from LC3B-I, was not changed after thalidomide treatment (Fig. 3C). CAIX, a marker of hypoxia induced by HIF-1 $\alpha$, may be a factor contributing to drug resistance in cancer cells (29). Upregulation of HIF-1 $\alpha$ started $4 \mathrm{~h}$ after thalidomide treatment and returned to basal level at $48 \mathrm{~h}$ (Fig. 3D). Increase in CAIX expression was observed $48 \mathrm{~h}$ after thalidomide treatment (Fig. 3D).

Thalidomide inhibition of BFTC905 cell growth is not via $V E G F, b F G F$, or $T N F-\alpha$. Treatment with 100 and $200 \mu \mathrm{M}$ thalidomide for 8 days significantly inhibited the number of viable BFTC905 cells ( $\mathrm{p}=0.02$ and $<0.001$, respectively, in two-way ANOVA; n=3; Fig. 4A). The difference between 100 and $200 \mu \mathrm{M}$ thalidomide treatment was statistically significant $(\mathrm{p}=0.003)$. Thalidomide at $200 \mu \mathrm{M}$ maintained the static growth of BFTC905 cells. VEGF (30) and bFGF (31) were secreted from TCC cells as growth factors, and thalidomide has been reported to decrease the expression of both (32). Exogenous administration of TNF- $\alpha$ promoted proliferation of TCC cells (33), and thalidomide enhanced the degradation of TNF- $\alpha$ mRNA (34). Besides, BDNF was also a survival factor for TCC in our previous study (20). Therefore, the secretion of these molecules after thalidomide treatment for $48 \mathrm{~h}$ was determined. Thalidomide at 200 and $500 \mu \mathrm{M}$ significantly inhibited the secretion of TNF- $\alpha$ and VEGF (n=3, Fig. 4B). Furthermore, exogenous VEGF (100 nM), bFGF (100 nM),
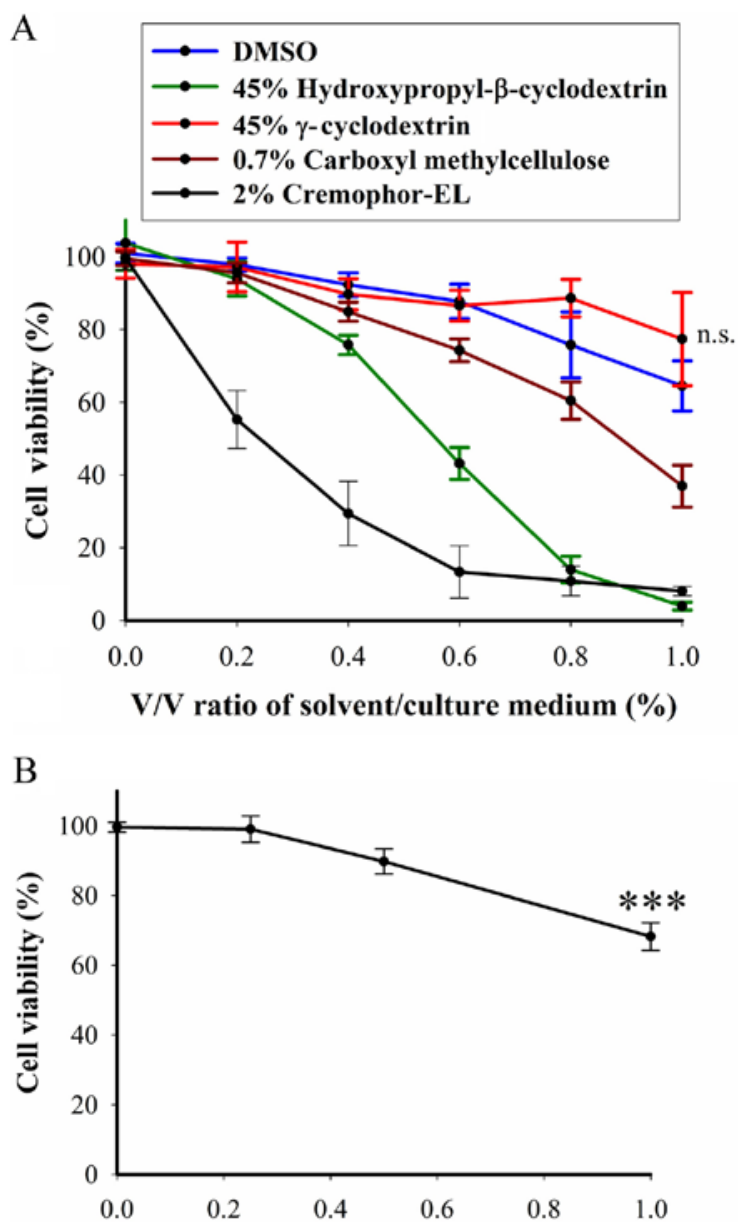

V/V ratio of $\mathbf{4 5} \% \gamma$-cyclodextrin/culture medium (\%)

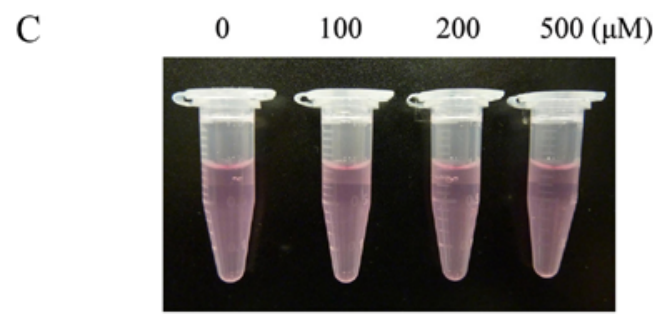

Figure 2. MTT assay was used to determine the viability of (A) BFTC905 cells after exposure to various solvents, and (B) primary human urothelial cells (HUC) after exposure to $45 \% \gamma$-cyclodextrin for $48 \mathrm{~h}$. (C) When thalidomide dissolved in $45 \% \gamma$-cyclodextrin was added to the culture medium, no sediment was observed. ${ }^{* *} 0.005 \leq \mathrm{p}<0.01$.

or TNF- $\alpha(100 \mathrm{ng} / \mathrm{ml})$ did not reverse thalidomide induced growth inhibition (Fig. 4C).

Thalidomide elicits quiescence in BFTC905 cells. After 48-h treatment, a significant accumulation of G0/G1 phase $[58.2 \pm 0.1$ vs. $65.1 \pm 0.6 \%$ after vehicle ( $\gamma$-cyclodextrin) vs. $200 \mu \mathrm{M}$ thalidomide treatment, $n=3, p=0.002$, Fig. $5 \mathrm{~A}$ and $\mathrm{B}]$ was observed. Cell cycle analysis by flow cytometry only reveals the proportional changes in each phase, so we further examined the specific cell cycle related proteins by western blotting (Fig. 5C and D). The dynamic expression of cyclins, cyclin dependent kinases, and related molecules in cell cycles is well established $(35,36)$. Downregulation of cyclin B and phospho-CDC2, the 
A

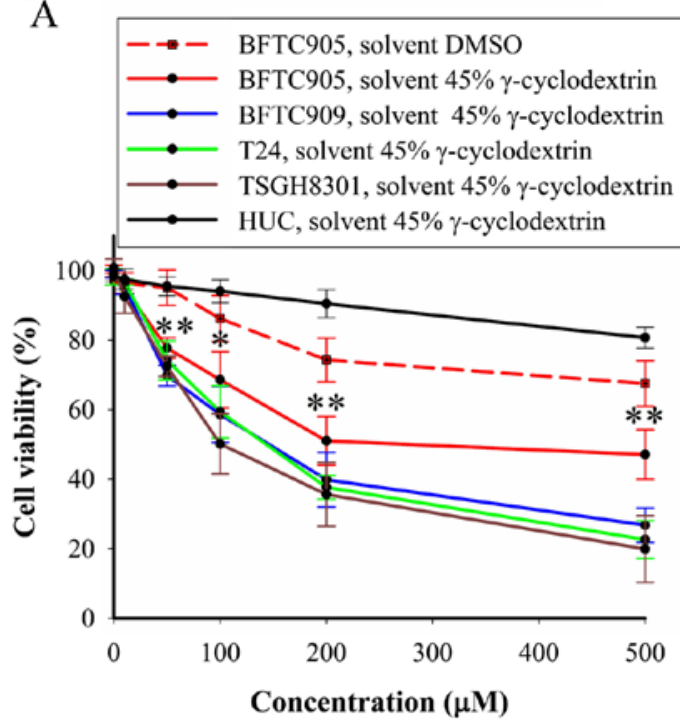

B

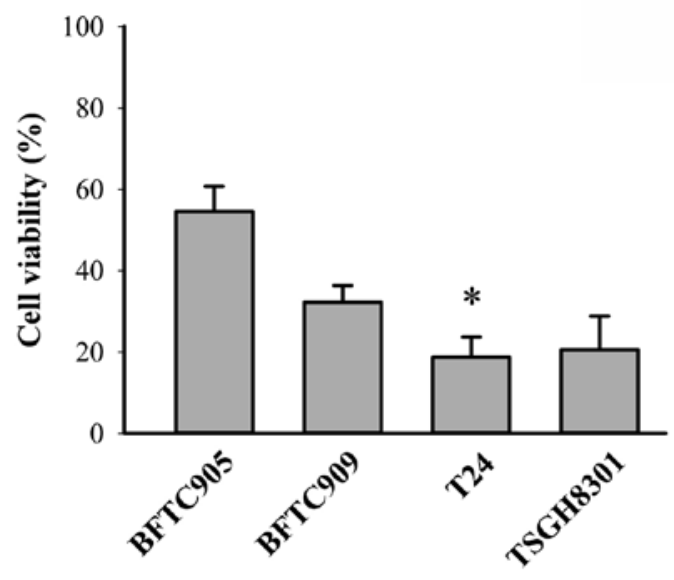

$\mathrm{C}$

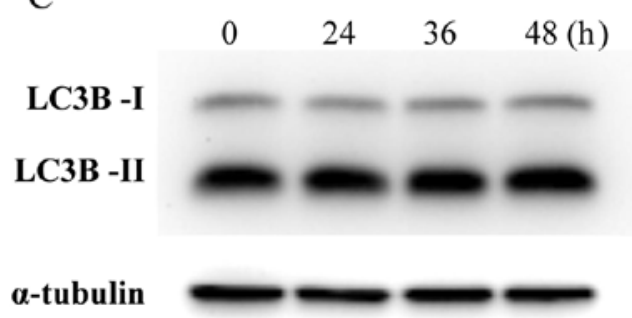

D

$$
\begin{array}{llllllllll}
0 & 1 & 2 & 4 & 6 & 8 & 12 & 24 & 48 & (\mathrm{~h})
\end{array}
$$

HIF-1 $\alpha$

\section{CAIX}

$\alpha$-tubulin

Figure 3. Cytotoxicity of thalidomide on TCC cells measured with MTT assay. (A) The viability of BFTC905, T24, TSGH8301, and BFTC909 cells was measured $48 \mathrm{~h}$ after treatment with thalidomide dissolved in 45\% $\gamma$-cyclodextrin. The viability of BFTC 905 cells treated with thalidomide dissolved in DMSO was also examined. The symbols ' $*$ ' and '**' indicate statistical significance of viability between thalidomide treatment and vehicle $45 \%$-cyclodextrin alone. (B) The viability of BFTC905, T24, TSGH8301, and BFTC909 cells was measured $48 \mathrm{~h}$ after co-treatment with thalidomide (200 $\mu$ M, dissolved in $45 \%$ $\gamma$-cyclodextrin) and gemcitabine (100 nM). (C and D) Representative western blots of (C) LC3B and (D) HIF-1 $\alpha$ and CAIX expression were examined within $48 \mathrm{~h}$ after treatment with $200 \mu \mathrm{M}$ thalidomide. ${ }^{*} 0.01 \leq \mathrm{p}<0.05,{ }^{* *} 0.005 \leq \mathrm{p}<0.01$.

markers of G2/M phase marker, indicated no G/M arrest. Downregulation of cyclin $\mathrm{A}$, which is expressed in $\mathrm{S}$ phase, indicated no $\mathrm{S}$ phase arrest. Decrease in phospho-CDK2 expression, which is expressed in late G1 phase or S phase, indicated no cell cycle stasis in late $\mathrm{G} 1$ and $\mathrm{S}$ phase. Decrease in expression of cyclin D1 and CDK4/6 (expressed in G1 phase before $\mathrm{R}$ point) and cyclin $\mathrm{E}$ (expressed in late G1 phase after $R$ point) indicated that thalidomide did not induce $G 1$ phase arrest. Due to the increased ratio of G0/G1 phase without G1 arrest, we substantiated that thalidomide induced G0 phase stasis, the so-called quiescence. The increased expression of $\mathrm{p} 27^{\mathrm{kip} 1}$, a potent inhibitor of cyclin-CDK complex formation, supported this idea (Fig. $5 \mathrm{E}$ ). $\mathrm{Ki}-67$ protein is present in the nucleus during all active phases of the cell cycle (G1, S, G2, and mitotic phase) but absent from quiescent cells (G0), so $\mathrm{Ki}-67$ is the most referenced marker for cellular proliferation $(37,38)$. As shown in Fig. 5E, expression of Ki-67 after 48-h thalidomide treatment was lower than control. Thus, we found that thalidomide promoted quiescence in BFTC905 cells.

Thalidomide induces apoptosis in BFTC905 cells. Cytoplasmic DNA fragments in BFTC905 cells, detected by binding of anti-histone plus anti-DNA antibodies, was significantly increased 48 -h after $200 \mu \mathrm{M}$ thalidomide treatment compared to vehicle $(n=3, p=0.03$; Fig. $6 A)$. Low basal levels and no significant changes of DNA fragments were detected in the culture medium of BFTC905 cells $48 \mathrm{~h}$ after thalidomide treatment ( $p=0.73$; Fig. 6A). Expression of cleaved caspase 3 , activated both by extrinsic and intrinsic pathways in apoptotic cells, was also increased after thalidomide treatment (Fig. 6B). These results indicated that thalidomide induced apoptosis of BFTC905 cells. Furthermore, we examined the changes of several anti-apoptosis or apoptosis related proteins. Expression of Bcl-2, BAX, TCTP, and cIAP1 were not changed (Fig. 6C). In contrast, expression of survivin and securin were downregulated. Expression of cIAP2 increased 24 and $36 \mathrm{~h}$ after thalidomide treatment, and returned to baseline at $48 \mathrm{~h}$ (Fig. 6D). Upregulation of Bcl-xL was observed after thalidomide treatment (Fig. 6D).

Lenalidomide and pomalidomide do not elicit cytotoxicity in BFTC905 cells. We further evaluated cytotoxicity of other IMiDs, lenalidomide and pomalidomide, on BFTC905 cells. Both drugs can be dissolved in DMSO and $\gamma$-cyclodextrin. After 48-h treatment, $200 \mu \mathrm{M}$ of both drugs dissolved in both solvents did not elicit significant cytotoxicity, but both at $500 \mu \mathrm{M}$ elicited significant cytotoxicity ( 15\%, Fig. 7A). 

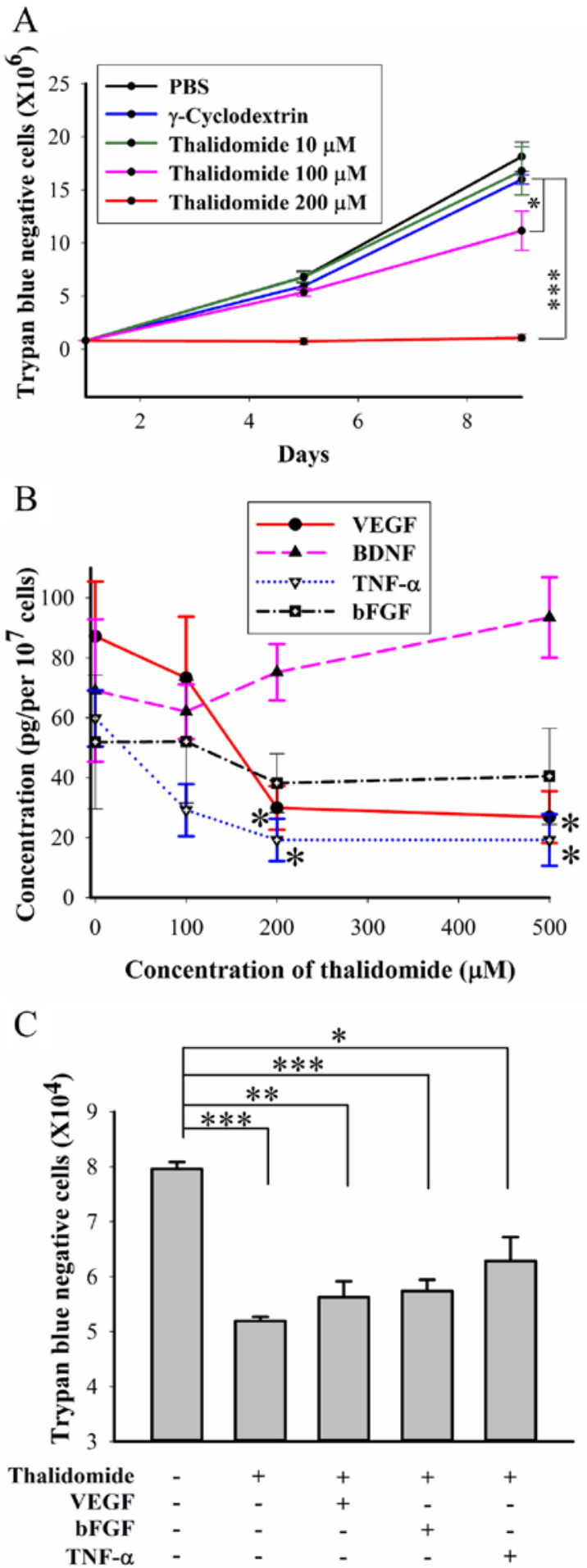

Figure 4. Roles of growth factors in BFTC905 cells treated with thalidomide (200 $\mu \mathrm{M}$, dissolved in $45 \% \gamma$-cyclodextrin). (A) After administration of thalidomide on days 1 and 5 , trypan blue-negative (viable) cell counts of BFTC905 cells were calculated on days 5 and 9. (B) Secretion of BDNF, VEGF, bFGF, and TNF- $\alpha$ from BFTC905 cells treated with thalidomide for $48 \mathrm{~h}$ was measured by ELISA. (C) After co-adminstration of thalidomide and $100 \mathrm{nM}$ VEGF, $100 \mathrm{nM}$ BDNF, $100 \mathrm{nM}$ bFGF, or $100 \mathrm{ng} / \mathrm{ml}$ TNF- $\alpha$ in culture medium with $1 \%$ FBS for $48 \mathrm{~h}$, trypan blue-negative cell counts of BFTC905 cells were calculated. ${ }^{*} 0.01 \leq \mathrm{p}<0.05,{ }^{* *} 0.005 \leq \mathrm{p}<0.01,{ }^{* * * *} \mathrm{p}<0.005$

Thalidomide and other IMiDs were shown to bind to cereblon and inhibited the associated E3 ubiquitin ligase activity (39), so we determined the roles of cereblon in the mechanism of the thalidomide effects. After 48-h treatment with IMiDs, no change of cereblon expression was observed (Fig. 7B). Furthermore, knockdown of cereblon by RNAi (Fig. 7C) did not change the cytotoxicity elicited by thalidomide, lenalidomide, or pomalidomide alone at $200 \mu \mathrm{M}$ (Fig. 7C). Therefore, cereblon plays no role in thalidomide for bladder cancer therapy.

Reactive oxidative species is produced after thalidomide treatment. Free radical-mediated oxidative damage was involved in the teratogenicity of thalidomide (40), so we evaluated the role of reactive oxidative species (ROS) in thalidomide-induced cytotoxicity. After 48-h treatment, only thalidomide, neither lenalidomide nor pomalidomide, triggered the production of ROS in BFTC905 cells (Fig. 8A). A progressive significant increase in total oxidant status (TOS) was found following 48-h treatment with thalidomide $(\mathrm{p}=0.02$ by one-way ANOVA, $n=3$; Fig. $8 \mathrm{~B}$ ). Administration of anti-oxidant catalase $(10,000 \mathrm{U} / \mathrm{ml}), \mathrm{NAC}(500 \mu \mathrm{M})$, and DTT (500 $\mathrm{nM}$ ) for $48 \mathrm{~h}$ all ameliorated thalidomide-induced cytotoxicity $(\mathrm{p}=0.04,0.03$, and 0.02 in catalase, NAC, DTT treatment group, respectively; $n=3$; Fig. $8 \mathrm{C}$ ). Thalidomide significantly elicited oxidative DNA damage detected by the formation of $8-\mathrm{OHdG}(\mathrm{p}=0.00004, \mathrm{n}=3$; Fig. 8D), and NAC significantly reversed the effect $(\mathrm{p}=0.0005$; Fig. 8D).

Thalidomide suppresses the invasion of BFTC905 cells induced by $T N F-\alpha$. For Matrigel invasion assay, chamber containing BFTC905 cells with medium deficient in nutrient is placed above the well containing full nutrient medium to create a nutrient gradient for chemotaxis of invasion by BFTC905 cells. Thalidomide exerted less cytotoxicity on BFTC905 cells in the medium containing 1\% FBS compared to normal medium containing 10\% FBS (Fig. 9A vs. Fig. 3A). We found that $50 \mu \mathrm{M}$ of thalidomide did not alter the viability of BFTC905 cells (Fig. 9A; $\mathrm{p}=0.142, \mathrm{n}=3$ ), and this concentration was chosen for the invasion experiment. However, no changes of invasion ability and related signalings were noted. Therefore, TNF- $\alpha$ induced invasion of TCC cells was followed (33). In agreement with a previous report (33), we found that exogenous administration of $100 \mathrm{ng} / \mathrm{ml} \mathrm{TNF}-\alpha$ for $48 \mathrm{~h}$, promoted proliferation of BFTC 905 cells with medium containing $1 \%$ FBS $(p=0.002, n=3$; Fig. 9B). However, in order to avoid the effects of proliferation in invasion experiment, TNF- $\alpha$ at $10 \mathrm{ng} / \mathrm{ml}$, which did not increase the number of BFTC905 cells in $1 \%$ FBS, was used $(p=0.4, n=3$; Fig. 9B). TNF- $\alpha$ promoted the invasive ability of BFTC905 cells in Matrigel assay $(\mathrm{p}=0.004, \mathrm{n}=10)$, and thalidomide significantly suppressed it $(\mathrm{p}=0.03$, Fig. $9 \mathrm{C})$. Transcription of $N F-\kappa B$ is involved in TNF- $\alpha$ triggered signaling pathways, the nuclear translocation of P65 after treatment with TNF- $\alpha$ and/or thalidomide was examined. Nuclear P65-positive cells were increased after TNF- $\alpha$ stimulation $(p=0.01, n=5)$, which were reversed to baseline by thalidomide treatment $(p=0.03$, Fig. 9D). The levels of MMP-9 and ICAM-1 have been found to be higher in high grade and more invasive type of bladder cancer $(41,42)$. Thus, we examined the total expression of MMP-9 and ICAM-1 and MMP-9 activity in the culture medium. TNF- $\alpha$ upregulated the expression of MMP-9 and ICAM-1, and thalidomide ameliorated their expression 
A
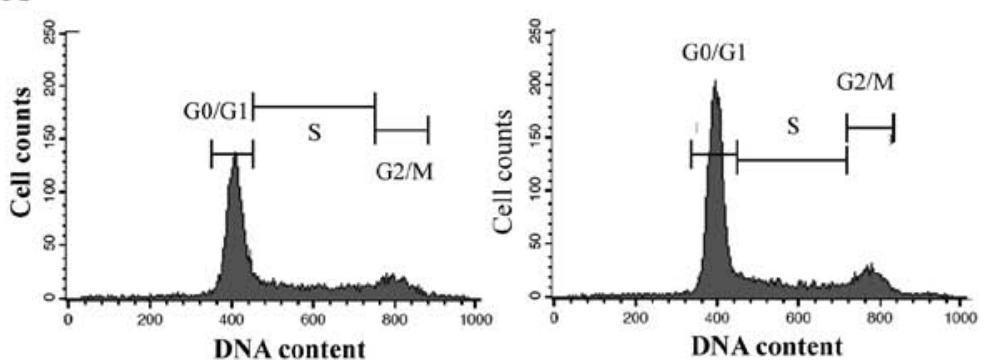

C

Cyclin A

Cyclin B

Cyclin D1

Cyclin E

a-tubulin
$0 \quad 24$

$48(\mathrm{~h})$
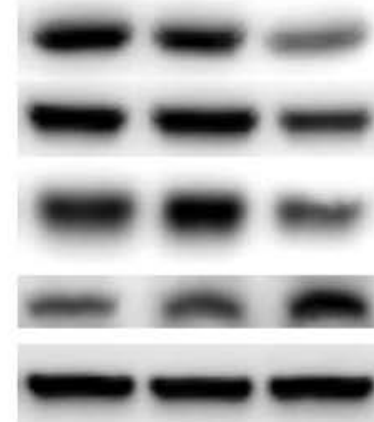

D

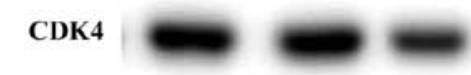

\section{CDK6}

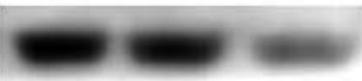

p-CDC2

p-CDK2

t-tubulin
B

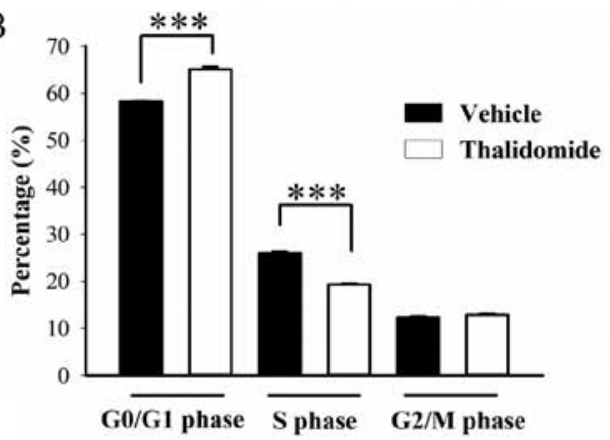

E

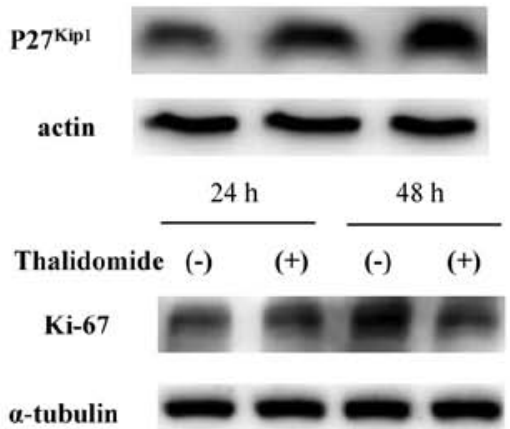

Figure 5. Changes of cell cycle and related proteins in BFTC905 cells after thalidomide (200 $\mu \mathrm{M}$, dissolved in 45\% $\gamma$-cyclodextrin) treatment. (A and B) Distribution and ratios of cell cycle changes were analyzed by flow cytometry $48 \mathrm{~h}$ after thalidomide treatment. Representative western blots of (C and D) cell cycle related protein as well as (E) p2 $7^{\mathrm{kipl}}$ and Ki-67 were examined within $48 \mathrm{~h}$ after thalidomide treatment. Experiments were repeated 3 times with similar results. Vehicle, $45 \% \gamma$-cyclodextrin. ${ }^{* * *} \mathrm{p}<0.005$.

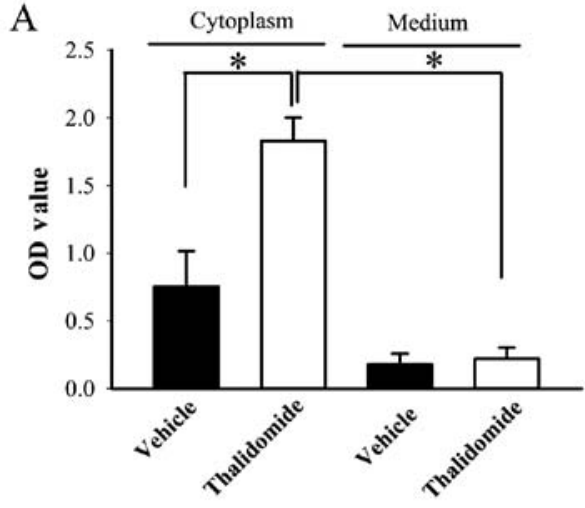

C

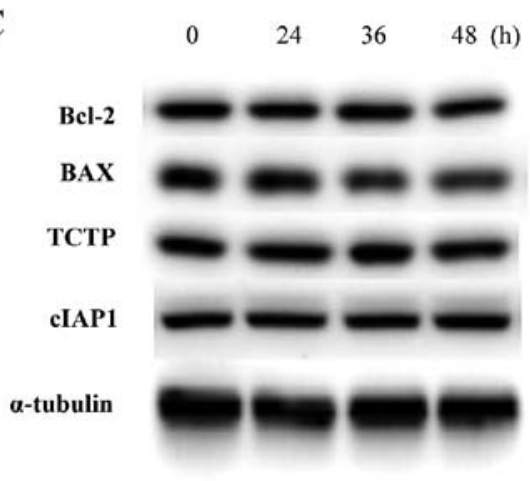

B

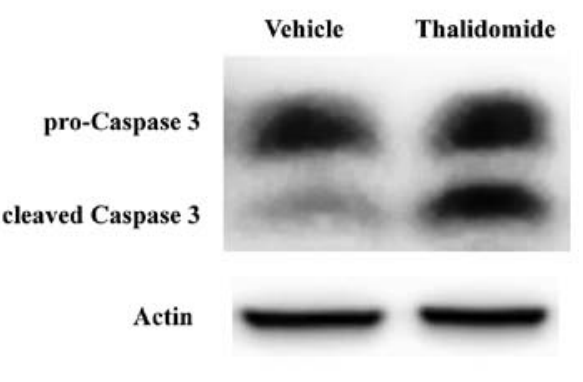

$\mathrm{D}$

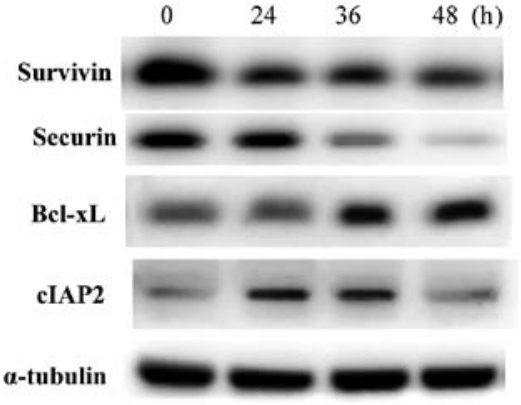

Figure 6. Apoptosis in BFTC905 cells after thalidomide (200 $\mu \mathrm{M}$, dissolved in $45 \% \gamma$-cyclodextrin) treatment. After thalidomide treatment for $48 \mathrm{~h}$, the supernatants of both the culture medium and the cytoplasmic fraction were collected. Increased expression of DNA fragments in the medium indicates necrosis due to membrane rupture, while increased expression in the cytoplasm alone indicates apoptosis. Representative western blots of (B) caspase 3 as well as (C and D) apoptosis and anti-apoptosis proteins were examined within $48 \mathrm{~h}$ after thalidomide treatment. Experiments were repeated 3 times with similar results. Vehicle, $45 \%$-cyclodextrin. ${ }^{*} 0.01 \leq \mathrm{p}<0.05$. 


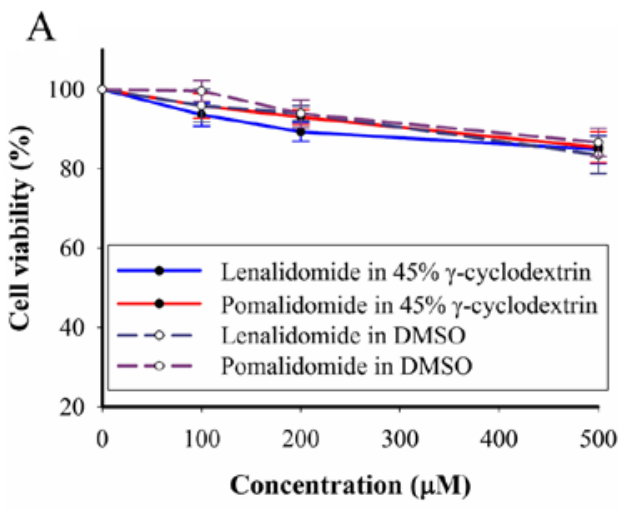

B

$\mathrm{C}$

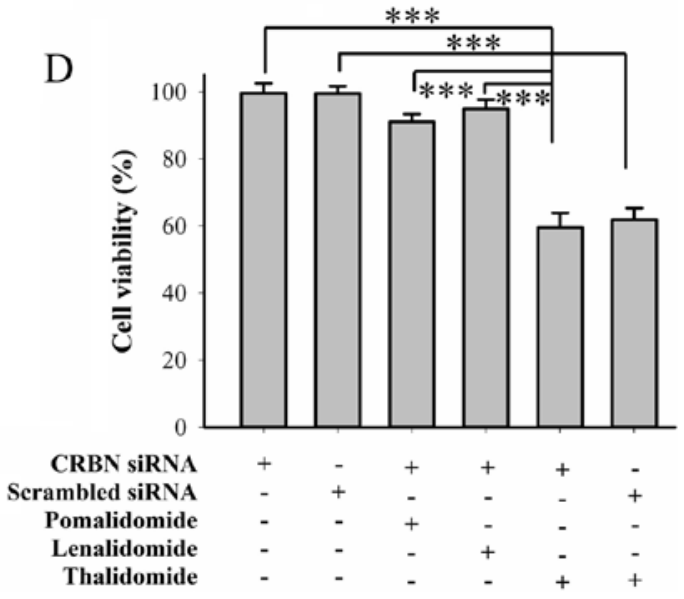

Figure 7. Role of cereblon in BFCT905 cells treated with IMiDs. (A) The viability of BFTC905 cells was measured by MTT assay $48 \mathrm{~h}$ after treatment with lenalidomide or pomalidomide dissolved in DMSO or 45\% $\gamma$-cyclodextrin. Western blots of cereblon expression were examined $48 \mathrm{~h}$ after (B) thalidomide, lenalidomide, or pomalidomide (all at $200 \mu \mathrm{M}$, dissolved in $45 \% \gamma$-cyclodextrin) treatment, and exposure to (C) cereblon siRNA or scrambled siRNA (as negative control). (D) The viability of BFTC 905 cells was measured by MTT assay $48 \mathrm{~h}$ after administration with IMiD and/or cereblon siRNA. ${ }^{* * *}$ p $<0.005$.
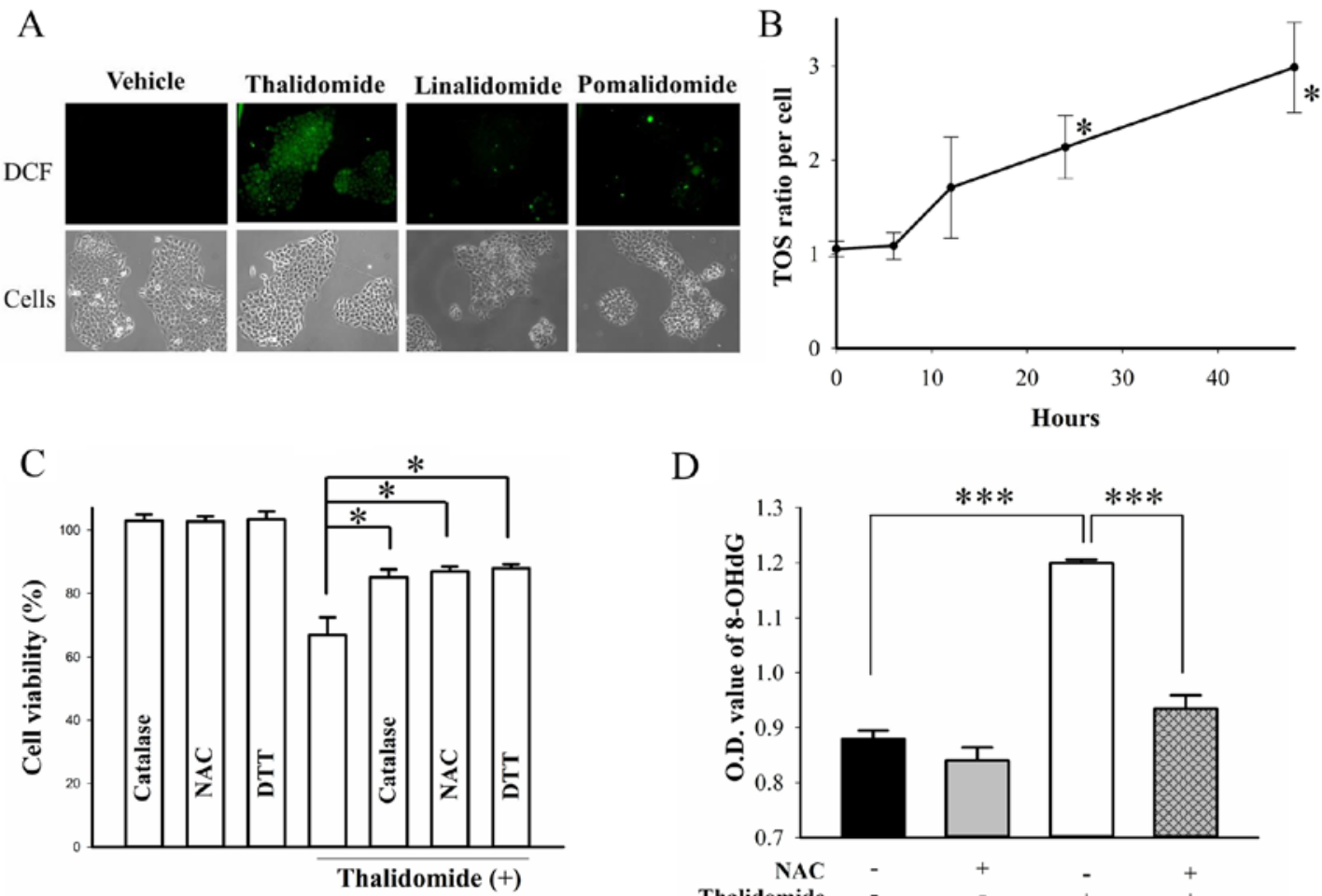

D

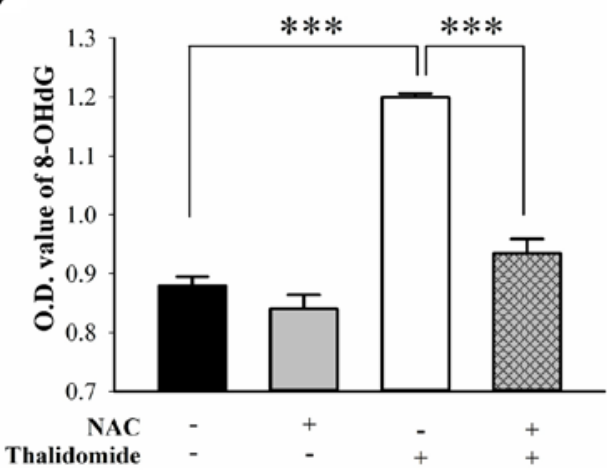

Figure 8. Role of ROS in BFCT905 cells treated with IMiDs (all at $200 \mu \mathrm{M}$, dissolved in $45 \% \gamma$-cyclodextrin). (A) Expression of DCF, proportional to the ROS level within the cell cytosol, was photographed $48 \mathrm{~h}$ after thalidomide, lenalidomide, or pomalidomide treatment (x100). (B) Ratios of total oxidant status (TOS) compared to vehicle exposure were measured after thalidomide treatment within $48 \mathrm{~h}$. (C) The viability of BFTC905 cells was measured by MTT assay $48 \mathrm{~h}$ after administration with thalidomide and/or anti-oxidants, including catalase (10,000 U/ml), NAC (500 $\mu \mathrm{M})$, and DTT (500 nM). (D) Formation of $8-\mathrm{OHdG}$, the marker of oxidative DNA damage after administration of thalidomide and/or NAC. Vehicle, $45 \% \gamma$-cyclodextrin. ${ }^{*} 0.01 \leq \mathrm{p}<0.05,{ }^{* * * *} \mathrm{p}<0.005$. 
A

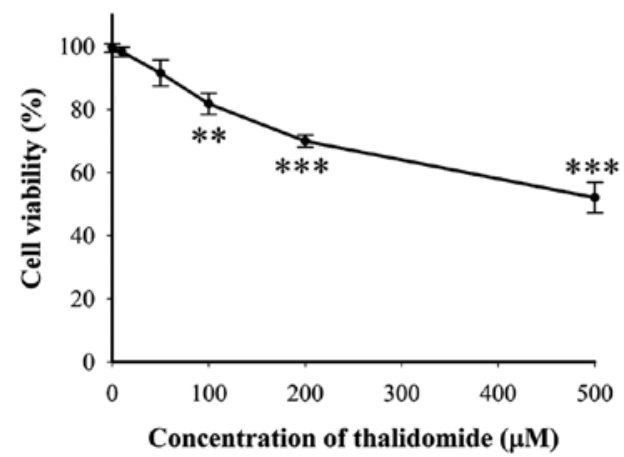

C

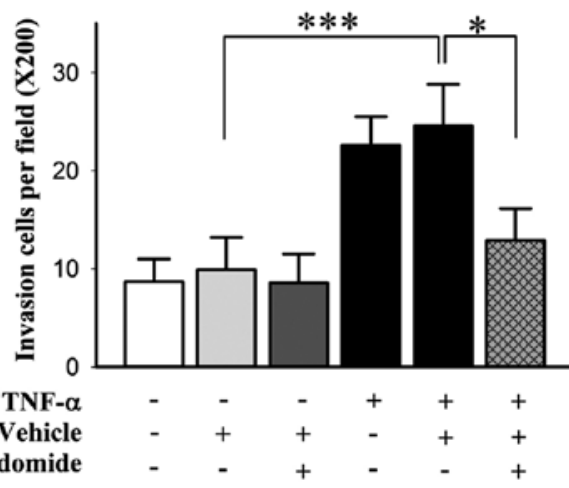

E

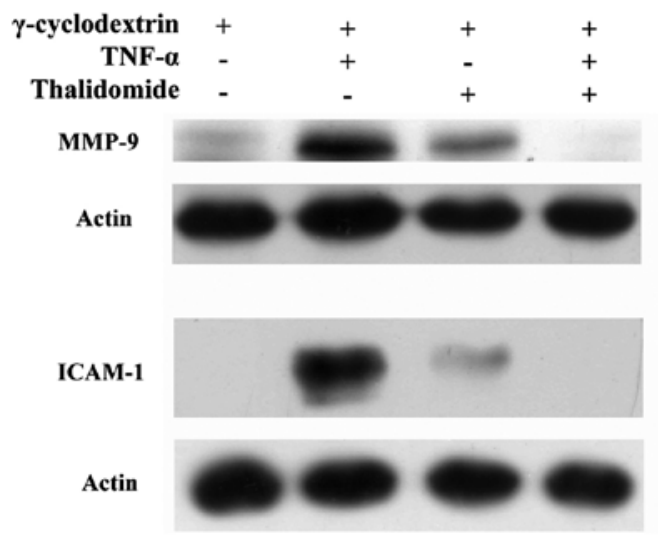

B

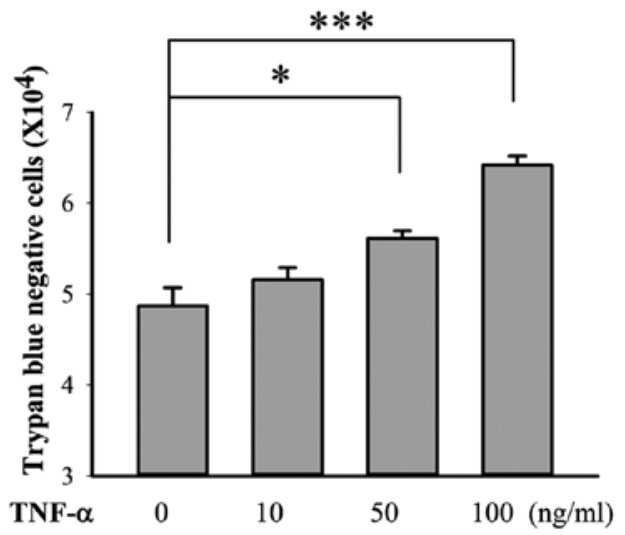

D

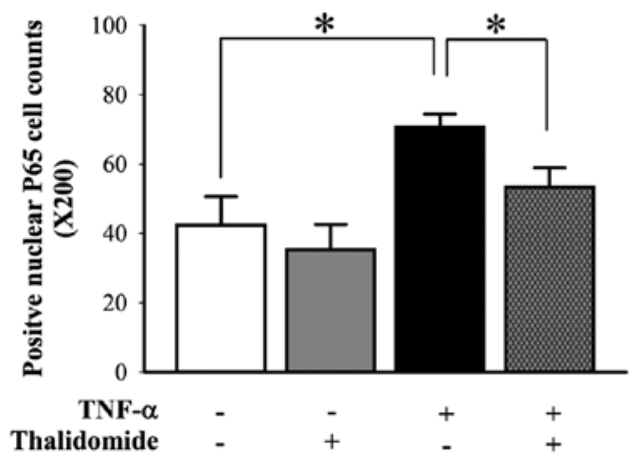

F

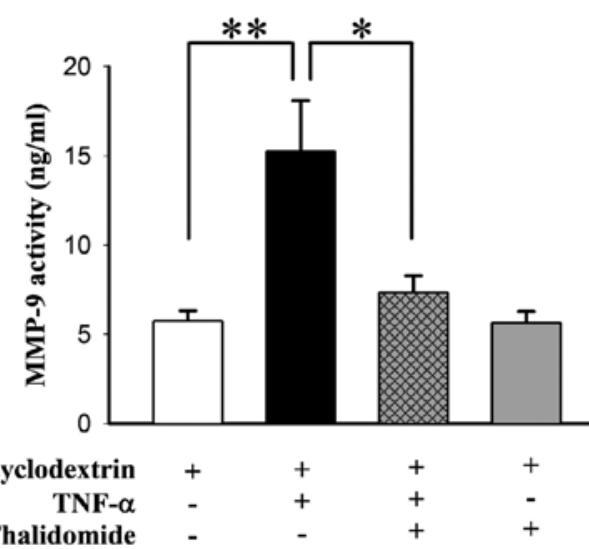

Figure 9. Thalidomide suppressed invasion of BFTC905 cells. Matrigel assay with deficient nutrient status (1\% FBS) in the chamber and full nutrient environment (10\% FBS) in the well to create a gradient for chemotaxis of invasion was used. (A) The viability of BFTC905 cells was measured by MTT assay $48 \mathrm{~h}$ after administration of thalidomide with deficient nutrient status. (B) After administration of TNF- $\alpha$ for $48 \mathrm{~h}$ with deficient nutrient status, trypan blue-negative cell counts were calculated. (C) Cancer cell invasion was detected by Matrigel assay after $10 \mathrm{ng} / \mathrm{ml}$ of TNF- $\alpha$ and/or $50 \mu \mathrm{M}$ of thalidomide. After 48 -h incubation, invading cells on the bottom surface of the membrane were counted under a microscope (x200). (D) Immunostaining of positive P65 expression in nuclei was counted under a microscope (x200) $48 \mathrm{~h}$ after TNF- $\alpha$ and/or thalidomide treatment. (E) Representative western blots of MMP-9 and ICAM-1 expression were examined $48 \mathrm{~h}$ after treatment with $200 \mu \mathrm{M}$ thalidomide. (F) Extracellular MMP-9 activity of BFTC905 cells was detected by ELISA $48 \mathrm{~h}$ following TNF- $\alpha$ and/or thalidomide treatment. Vehicle, $45 \% \gamma$-cyclodextrin. ${ }^{*} 0.01 \leq \mathrm{p}<0.05,{ }^{* *} 0.005 \leq \mathrm{p}<0.01,{ }^{* * *} \mathrm{p}<0.005$.

after TNF- $\alpha$ stimulation (Fig. 9E). MMP-9 activity was also significantly increased by TNF- $\alpha$ stimulation $(\mathrm{p}=0.008$, $\mathrm{n}=5$; Fig. 9F). Thalidomide suppressed MMP-9 activity after TNF- $\alpha$ stimulation ( $\mathrm{p}=0.03$, Fig. 9F).

Effects of thalidomide on BFTC905 xenografts in vivo. When thalidomide treatment was initiated on the day of BFTC905 cell implantation, almost no xenograft tumor formation was observed (Fig. 10A). The difference of tumor growth curve between thalidomide and vehicle treatment revealed statistical significance $(\mathrm{p}<0.0001$ by two-way ANOVA, $n=6)$. To evaluate the possible therapeutic effect, thalidomide treatment was administered after tumor formation (2 weeks after BFTC905 cell implantation) in another experiment 


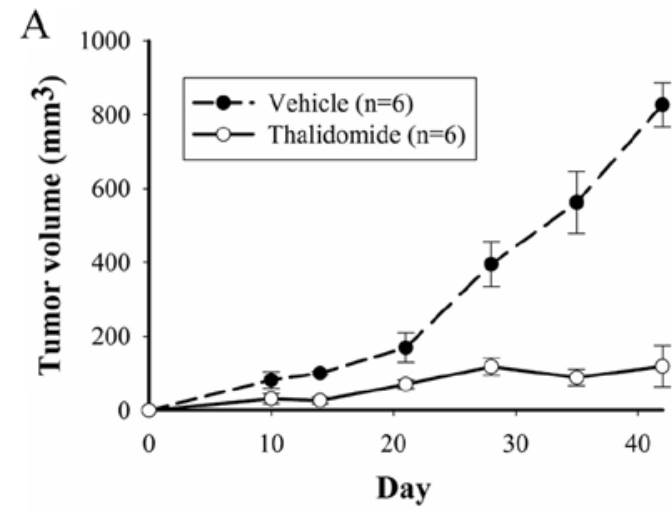

$\mathrm{C}$

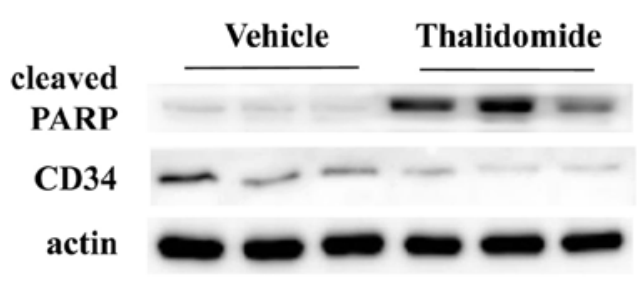

$\mathrm{E}$

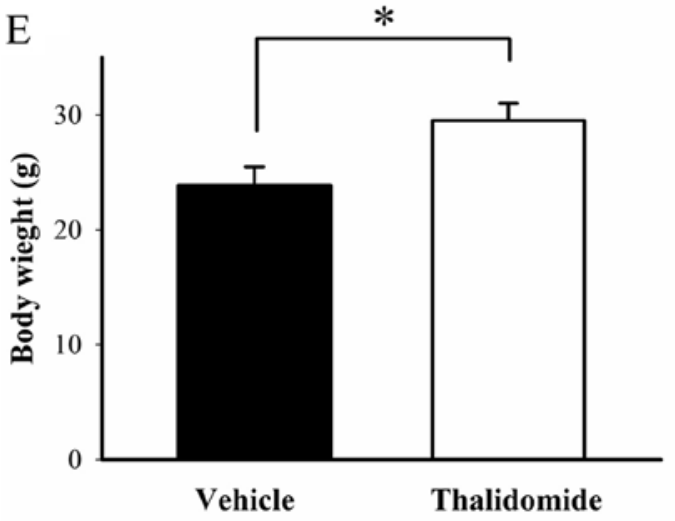

B

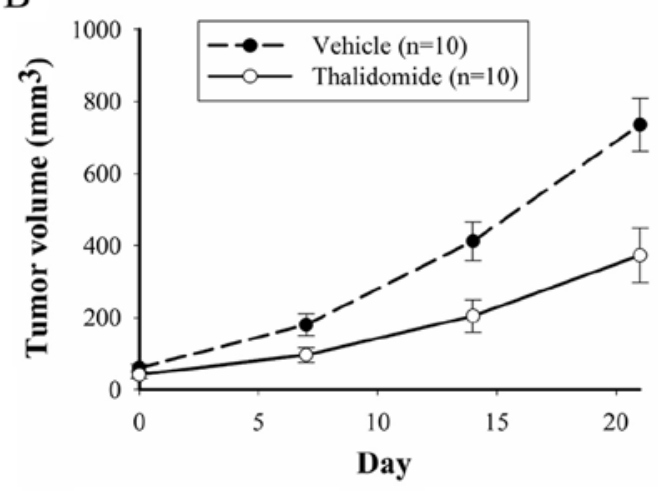

$\mathrm{D}$
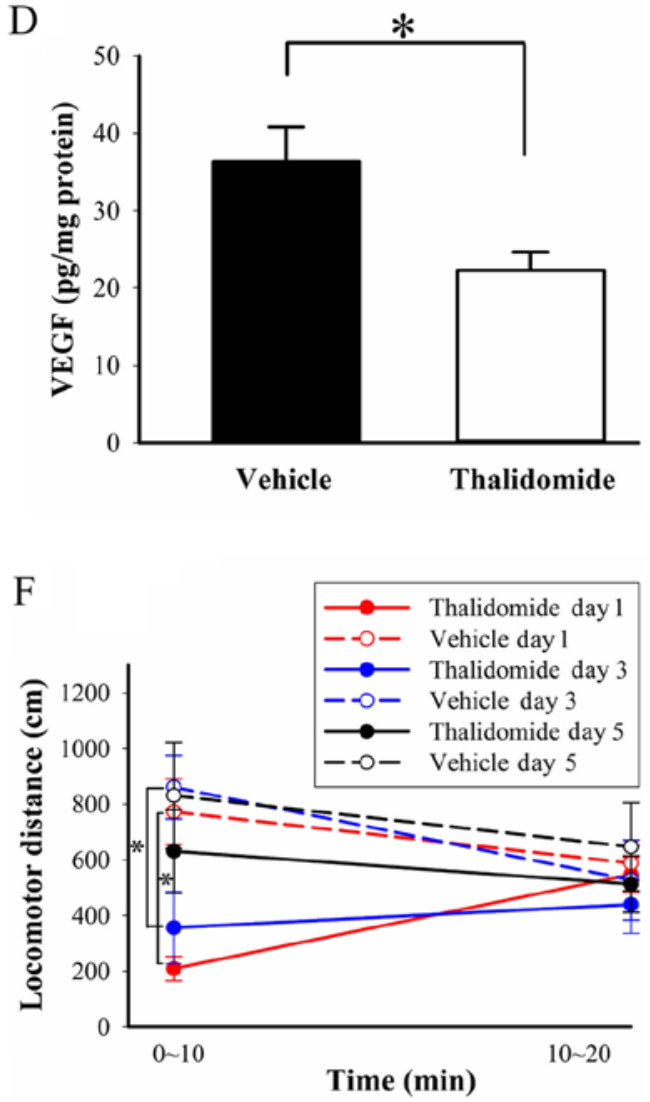

Figure 10. Effects of thalidomide in BFTC905 xenograft model of SCID mice. Treatment with $250 \mathrm{mg} / \mathrm{kg}$ of thalidomide administered s.c. into the loading site of cancer cells when the tumor was impalpable or directly into the tumor 3 times per week (W1, 3, 5) (A) on the day of implantation, and (B) 2 weeks after implantation of cancer cells. The following results were obtained after sacrifice from (B), the investigation of post-treatment strategy. (C) Representative western blots of cleaved PARP and CD34 expression in three repeated samples were examined. (D) VEGF in xenograft tumors were detected by ELISA. (E) Body weights of mice were measured. (F) Locomoter distance 0-10 min and 10-20 min after thalidomide infection in the first week was calculated. Vehicle, $45 \%$-cyclodextrin. ${ }^{*} 0.01 \leq \mathrm{p}<0.05$.

(post-treatment strategy). After thalidomide treatment for 3 weeks, the difference of tumor volume between thalidomide and vehicle treatment also revealed statistical significance ( $p<0.0001$ by two-way ANOVA, n=10; Fig. 10B). In addition, the significant difference was observed at 7 days after treatment $\left(96.4 \pm 20.7\right.$ and $180.3 \pm 30.1 \mathrm{~mm}^{3}$ for thalidomide and vehicle treatment, respectively; $\mathrm{p}=0.03$ ). Although the tumor sizes were significantly increased after thalidomide treatment $(\mathrm{p}<0.001$ in one-way ANOVA), the average tumor sizes in the thalidomide group were only half of those in the control group $(\mathrm{p}=0.003)$. After 3 -week treatment, the mean tumor volume in thalidomide and vehicle group was $372.7 \pm 75.7$ and
$735.7 \pm 73.6 \mathrm{~mm}^{3}$, respectively. In the following results, we examined the changes of cleaved PARP, CD34 and VEGF in the xenograft tumors for the post-treatment strategy. Cleaved PARP facilitates cellular disassembly and promotes apoptosis (43), and thalidomide treatment increased the expression of cleaved PARP in three repeated samples (Fig. 10C). CD34 is a marker for angiogenesis in bladder cancer (44). Expression of CD34 was decreased in three repeated samples of thalidomide therapy (Fig. 10C). VEGF levels detected by ELISA were also significantly decreased after thalidomide treatment $(\mathrm{p}=0.02$, $\mathrm{n}=5$; Fig. 10D). Grossly, no overt activity changes and no distal organ metastases were observed. 
Cachexia, regardless of disease category or treatment modality, is a problem for cancer patients (45). However, in our study, average body weight in thalidomide group was significantly higher than vehicle group $(29.5 \pm 1.5$ vs. $23.9 \pm 1.6 \mathrm{~g}$ for thalidomide and vehicle group, respectively; $n=10, p=0.01$, Fig. 10E). Sedative effects of thalidomide have been reported in human (46), so we also examined this adverse effect in mice. A significantly sedative effect with lower locomotor distance $(209.3 \pm 43.7$ and $772.9 \pm 117.7 \mathrm{~cm}$ for thalidomide and vehicle treatment, respectively; $n=3, p=0.01$ ) was observed within the first $10 \mathrm{~min}$ after injecting the first dose of thalidomide to mice (Fig. 10F). The locomotor distance in the first $10 \mathrm{~min}$ after the second administration of thalidomide also significantly less (356.6 \pm 129.6 and $861.7 \pm 114.0 \mathrm{~cm}$ for thalidomide and vehicle treatment, respectively; $n=3, p=0.04$ ). The locomotor distance in the first $10 \mathrm{~min}$ after the third administration showed no difference in either group $(\mathrm{p}=0.21)$. The locomotor distance in the 10-20 min after the first, second, and third administration was similar for both groups $(\mathrm{p}=0.66,0.65$ and 0.52 , respectively).

\section{Discussion}

In previous studies, thalidomide was usually dissolved in DMSO $(18,47-49)$ or CMC (50-52). However, there are only a few in vitro thalidomide studies, and few researchers pay attention to the solubility of thalidomide. Some in vitro studies reported that the inhibitory effect of thalidomide may be partially attributed to the solvent DMSO alone $(53,54)$, and our results were compatible with these studies. Cyclodextrins, cyclic oligosaccharides with a hydrophilic outer surface and a lipophilic central cavity to form inclusion complexes, can improve solubility and permeability (55). Some studies reported that thalidomide dissolved in ether-7 $\beta$-cyclodextrin or hydroxypropyl- $\beta$-cyclodextrin improved the aqueous solubility (56-58). Kratz et al tested the solubility of thalidomide with $\alpha$-cyclodextrin, $\beta$-cyclodextrin, and $\gamma$-cyclodextrin (56). Thalidomide dissolved in $\beta$-cyclodextrin showed the best solubility, however, cytotoxicity was not determined.

There are few in vitro studies of thalidomide on solid malignancy cells. The concentration of thalidomide used in this study might be relative high for BFTC905 cells, so we tried to find the reasons. Release rate of drugs using cyclodextrin as a carrier might be rapid, so insufficient intracellular concentration due to thalidomide $\gamma$-cyclodextrin complex could be excluded (59). Compensatory increase in the expression of anti-apoptotic protein Bcl-xL was found in our experiment, but overexpression of $\mathrm{Bcl}-\mathrm{xL}$ was not correlated with the recurrence and survival of bladder cancer patients (60). In our previous study, upregulation of securin and Bcl-2 in BFTC905 cells may be a compensatory mechanism for gemcitabine resistance (22). Downregulated expression of securin, but no changes of $\mathrm{Bcl}-2$ expression were observed after thalidomide treatment. This may explain the lack of additively therapeutic effects of gemcitabine plus thalidomide combination in this study, and the much less potency of thalidomide than YM155, the survivin inhibitor which decreased both securin and Bcl-2 expression in our previous study (22). However, thalidomide has some advantages for the potential therapy of bladder cancer clinically, for examples, available in the market and possible oral administration. Second, hypoxia-inducible CAIX generates protons that contribute to acidification of external $\mathrm{pH}$ and provides bicarbonate to neutralize intracellular $\mathrm{pH}$ through the inward transporter. Such $\mathrm{pH}$ maintenance plays a role in the regulation of cell proliferation, cell adhesion, and tumor progression to mediate drug resistance (61). Any treatment aimed to inhibit HIF-1 $\alpha$-CAIX axis signaling pathways as a therapy potential for bladder cancer has been investigated (62). HIF-1 $\alpha$ induced CAIX upregulation was observed after thalidomide treatment in this study. This may also contribute to the decreased potency of thalidomide on BFTC905 cells. Third, non-cycling quiescent cells can take the time to repair the damage after cancer therapy $(63,64)$. The promoting effects of thalidomide to increase quiescent TCC cells, although only $7 \%$ in magnitude, may also partially explain the relatively high concentration of thalidomide used in this study.

In the present study, the growth inhibition of thalidomide on TCC cells resulted mainly from apoptotic effects. The cytotoxic effects of $500 \mu \mathrm{M}$ thalidomide on primary HUC cells may result from $\gamma$-cyclodextrin per se. Our result demonstrated the safety to normal urothelial cells with administration of $200 \mu \mathrm{M}$ thalidomide dissolved in $45 \% \gamma$-cyclodextrin. Some studies also reported the apoptotic activity of thalidomide (17,65). In agreement with a previous study (66), we found no changes of cell cycle after thalidomide treatment. Downregulation of survivin and securin by thalidomide is the novel findings in our study. Survivin, a member of the inhibitor of apoptosis protein family, has been shown to be a prognostic parameter of bladder cancer (67). Previously we reported that securin was overexpressed in human TCC specimens (68). Therefore, decreased expression of survivin and securin is a good indicator of thalidomide therapy for bladder cancer. Jian et al demonstrated that inhibition of low-grade TCC cells by lenalidomide was attributable to not only its direct tumor apoptotic but also anti-angiogenic activity (69), so we compared cytotoxicity of three IMiDs on gemcitabine-resistant TCC cells. Previous research demonstrated cereblon-dependent anti-neoplastic activity of IMiDs in cancer cells $(70,71)$. Depletion of cereblon endowed cancer cells with therapeutic resistance to IMiDs. However, cereblon plays no role in thalidomide-induced cytotoxicity in BFTC905 cells. Lack of correlation with cereblon and IMiDs in human myeloma cell lines has also been reported (72). ROS is a double-edged sword in cancer biology. Puskás et al demonstrated that lipid droplet binding thalidomide analogs induced oxidative stress in cancer cells (73). Teratogenetic mechanism of thalidomide may be caused by enzymes catalyzing thalidomide to a free radical intermediate, and further generating ROS to modify DNA in many ways, including the formation of $8-\mathrm{OHdG}$ (40). Our results were consistent with the pathophysiology of thalidomide-induced damage in embryos.

BFTC905 cells possess greater invasive ability (23), so any treatment which suppresses their invasion may be a good strategy for bladder cancer therapy. The limitation of cell culture experiments is that sometimes the in vitro environment may not mimic the in vivo one. Due to lack of stimulated or stress condition in cell culture system, we followed the model of TNF- $\alpha$ induced invasion in TCC cells (33). We used only $10 \%$ of TNF- $\alpha$ stimulation compared to Lee et al (33) to avoid the proliferative effects on invasion. Thalidomide exerted its effect on downregulation of NF- $\mathrm{NB}$-induced ICAM-1 through 
inhibition of degradation of $\mathrm{I \kappa B}(18,74)$. Thalidomide decreased the mRNA, protein synthesis, and secretion of MMP-9 (75). This evidence was also found in our thalidomide-treated BFTC905 cells.

Although thalidomide significantly induced apoptosis and inhibited angiogenesis in our animal experiments, thalidomide only suppressed the growth rates of BFTC905 xenografts. Nonetheless, it is consistent with the in vitro findings that some compensatory or resistant mechanisms were found in thalidomide-treated BFTC905 cells. Comparing to other studies $(200 \mathrm{mg} / \mathrm{kg} / \mathrm{d}=1,400 \mathrm{mg} / \mathrm{kg} / \mathrm{w})$, less weekly administration of thalidomide $(250 \mathrm{mg} / \mathrm{kg}$ three times per week $=750 \mathrm{mg} / \mathrm{kg} / \mathrm{w})$ in our study might be another explanation $(76,77)$. Therefore, combination of thalidomide with other drug(s) might be the next strategy. Unfortunately, gemcitabine plus thalidomide did not show additive cytotoxicity on BFTC905 cells in vitro. Better drug combinations should be tested in the future. Beyond the detection of VEGF in tumors, immunostaining of CD34 to analyze microvascular density, a specific marker of endothelial cells, is a common method for the evaluation of angiogenesis (78). We have also examined the localization of CD34 in BFTC905 xenograft tumors by immunohistochemistry, but few and scattered distribution of positive CD34 endothelial cells were found (data not shown). So western blotting was used instead of immunohistochemistry for CD34 in xenograft tumors. Low expression of CD34 measured by western blotting was correlated with the findings by immunohistochemistry. Thalidomide was effective in attenuating weight loss in cancer patients with cachexia (79), and our study also showed similar results. No animal studies report the sedative effect after thalidomide treatment. Our observation that thalidomide exerted significant somnolence in mice may be due to the higher dose of injections. Patients developed tolerance to the side effect of sedation (80), and the present study is compatible with clinical usage of thalidomide.

There are limitations in this study. We cannot characterize the thalidomide $\gamma$-cyclodextrin complex, for example, using $\mathrm{X}$-ray powder diffractometry. In addition, we cannot detect the concentration of thalidomide in cells. Lack of co-culture of natural killer cells and TCC cells to examine the effects of IMiDs on immune cells (81) is another limitation. However, in the present study, we demonstrated the potential effects of thalidomide therapy, including induction of apoptosis through oxidative stress, inhibition of angiogenesis through decreases in VEGF production and secretion, and suppression of invasive ability via downregulation of MMP-9 and ICAM-1, for gemcitabine-resistant bladder cancer cells in vitro and in vivo.

\section{Acknowledgements}

This study was supported by a grant-in-aid from Tzu Chi General Hospital, Hualien 970, Taiwan.

\section{References}

1. Murta-Nascimento C, Schmitz-Dräger BJ, Zeegers MP, Steineck G, Kogevinas M, Real FX and Malats N: Epidemiology of urinary bladder cancer: From tumor development to patient's death. World J Urol 25: 285-295, 2007.

2. Tavora F and Epstein JI: Bladder cancer, pathological classification and staging. BJU Int 102B: 1216-1220, 2008.
3. Hall MC, Chang SS, Dalbagni G, Pruthi RS, Seigne JD, Skinner EC, Wolf JS Jr and Schellhammer PF: Guideline for the management of nonmuscle invasive bladder cancer (stages Ta, T1, and Tis): 2007 update. J Urol 178: 2314-2330, 2007.

4. Witjes JA, Compérat E, Cowan NC, De Santis M, Gakis G, Lebret T, Ribal MJ, Van der Heijden AG and Sherif A; European Association of Urology: EAU guidelines on muscle-invasive and metastatic bladder cancer: Summary of the 2013 guidelines. Eur Urol 65: 778-792, 2014.

5. von der Maase H, Hansen SW, Roberts JT, Dogliotti L, Oliver T, Moore MJ, Bodrogi I, Albers P, Knuth A, Lippert CM, et al: Gemcitabine and cisplatin versus methotrexate, vinblastine, doxorubicin, and cisplatin in advanced or metastatic bladder cancer: Results of a large, randomized, multinational, multicenter, phase III study. J Clin Oncol 18: 3068-3077, 2000.

6. George L, Bladou F, Bardou VJ, Gravis G, Tallet A, Alzieu C, Serment G and Salem N: Clinical outcome in patients with locally advanced bladder carcinoma treated with conservative multimodality therapy. Urology 64: 488-493, 2004.

7. Bartlett JB, Dredge K and Dalgleish AG: The evolution of thalidomide and its IMiD derivatives as anticancer agents. Nat Rev Cancer 4: 314-322, 2004.

8. Kumar S and Rajkumar SV: Thalidomide and dexamethasone: Therapy for multiple myeloma. Expert Rev Anticancer Ther 5: 759-766, 2005.

9. Hideshima T, Chauhan D, Shima Y, Raje N, Davies FE, Tai YT, Treon SP, Lin B, Schlossman RL, Richardson P, et al: Thalidomide and its analogs overcome drug resistance of human multiple myeloma cells to conventional therapy. Blood 96: 2943-2950, 2000.

10. Gras J: Pomalidomide for patients with multiple myeloma. Drugs Today (Barc) 49: 555-562, 2013.

11. Andhavarapu $S$ and Roy V: Immunomodulatory drugs in multiple myeloma. Expert Rev Hematol 6: 69-82, 2013.

12. Chanan-Khan AA, Swaika A, Paulus A, Kumar SK, Mikhael JR, Rajkumar SV, Dispenzieri A and Lacy MQ: Pomalidomide: The new immunomodulatory agent for the treatment of multiple myeloma. Blood Cancer J 3: e143, 2013.

13. Pinter M, Wichlas M, Schmid K, Plank C, Müller C, Wrba F and Peck-Radosavljevic M: Thalidomide in advanced hepatocellular carcinoma as antiangiogenic treatment approach: A phase I/II trial. Eur J Gastroenterol Hepatol 20: 1012-1019, 2008.

14. Yau T, Chan P, Wong H, Ng KK, Chok SH, Cheung TT, Lam V, Epstein RJ, Fan ST and Poon RT: Efficacy and tolerability of low-dose thalidomide as first-line systemic treatment of patients with advanced hepatocellular carcinoma. Oncology 72 (Suppl 1): S67-S71, 2007.

15. Fadul CE, Kingman LS, Meyer LP, Cole BF, Eskey CJ, Rhodes CH, Roberts DW, Newton HB and Pipas JM: A phase II study of thalidomide and irinotecan for treatment of glioblastoma multiforme. J Neurooncol 90: 229-235, 2008.

16. Puduvalli VK, Giglio P, Groves MD, Hess KR, Gilbert MR, Mahankali S, Jackson EF, Levin VA, Conrad CA, Hsu SH, et al: Phase II trial of irinotecan and thalidomide in adults with recurrent glioblastoma multiforme. Neuro-oncol 10: 216-222, 2008.

17. Sun P, Zhang LM, Sun DJ and Dong LL: Inhibitory effect of thalidomide on growth of human hepatoma cell line SMMC-7721 cells. Zhonghua Zhong Liu Za Zhi 31: 582-586, 2009 (In Chinese).

18. Lin YC, Shun CT, Wu MS and Chen CC: A novel anticancer effect of thalidomide: Inhibition of intercellular adhesion molecule1-mediated cell invasion and metastasis through suppression of nuclear factor-kappaB. Clin Cancer Res 12: 7165-7173, 2006.

19. Tzeng CC, Liu HS, Li C, Jin YT, Chen RM, Yang WH and Lin JS: Characterization of two urothelium cancer cell lines derived from a blackfoot disease endemic area in Taiwan. Anticancer Res 16A: 1797-1804, 1996.

20. Huang YT, Lai PC, Wu CC, Hsu SH, Cheng CC, Lan YF and Chiu TH: BDNF mediated TrkB activation is a survival signal for transitional cell carcinoma cells. Int J Oncol 36: 1469-1476, 2010.

21. Lai PC, Yang YC, Cheng CC, Chiu TH and Huang YT: Brainderived neurotrophic factor plus vascular endothelial growth factor additively promotes early growth of the transitional cell carcinoma cell line BFTC905 in vitro and in vivo. Tzu Chi Med J 25: 155-160, 2013 .

22. Huang YT, Cheng CC, Lin TC, Chiu TH and Lai PC: Therapeutic potential of sepantronium bromide YM155 in gemcitabine-resistant human urothelial carcinoma cells. Oncol Rep 31: 771-780, 2014. 
23. Huang YT, Lai PC, Wu CC, Cheng CC and Chiu TH: TrkB antibody elicits cytotoxicity and suppresses migration/invasion of transitional cell carcinoma cells. Int J Oncol 37: 943-949, 2010.

24. Strober W: Trypan blue exclusion test of cell viability. Curr Protoc Immunol 3 (Appendix): 3B, 2001.

25. Lai PC, Fang TC, Cheng CC, Chiu TH and Huang YT: Lestaurtinib is cytotoxic to oxaliplatin-resistant transitional cell carcinoma cell line T24 in vitro. Tzu Chi Med J 22: 125-130, 2010.

26. Erel O: A new automated colorimetric method for measuring total oxidant status. Clin Biochem 38: 1103-1111, 2005.

27. Hsu CW, Chen CY, Wang CS and Chiu TH: Caffeine and a selective adenosine $\mathrm{A} 2 \mathrm{~A}$ receptor antagonist induce reward and sensitization behavior associated with increased phospho-Thr75 DARPP-32 in mice. Psychopharmacology (Berl) 204: 313-325, 2009.

28. Buchser WJ, Laskow TC, Pavlik PJ, Lin HM and Lotze MT: Cellmediated autophagy promotes cancer cell survival. Cancer Res 72: 2970-2979, 2012.

29. Zheng G, Zhou M, Ou X, Peng B, Yu Y, Kong F, Ouyang Y and $\mathrm{He} \mathrm{Z}$ : Identification of carbonic anhydrase 9 as a contributor to pingyangmycin-induced drug resistance in human tongue cancer cells. FEBS J 277: 4506-4518, 2010.

30. Wu W, Shu X, Hovsepyan H, Mosteller RD and Broek D: VEGF receptor expression and signaling in human bladder tumors Oncogene 22: 3361-3370, 2003.

31. Allen LE and Maher PA: Expression of basic fibroblast growth factor and its receptor in an invasive bladder carcinoma cell line. J Cell Physiol 155: 368-375, 1993.

32. Li X, Liu X, Wang J, Wang Z, Jiang W, Reed E, Zhang Y, Liu Y and Li QQ: Thalidomide down-regulates the expression of VEGF and bFGF in cisplatin-resistant human lung carcinoma cells. Anticancer Res 23B: 2481-2487, 2003.

33. Lee EJ, Kim WJ and Moon SK: Cordycepin suppresses TNF-alpha-induced invasion, migration and matrix metalloproteinase-9 expression in human bladder cancer cells. Phytother Res 24: 1755-1761, 2010.

34. Moreira AL, Sampaio EP, Zmuidzinas A, Frindt P, Smith KA and Kaplan G: Thalidomide exerts its inhibitory action on tumor necrosis factor alpha by enhancing mRNA degradation. J Exp Med 177: 1675-1680, 1993.

35. Sherr CJ: Cancer cell cycles. Science 274: 1672-1677, 1996.

36. Hunter T and Pines J: Cyclins and cancer. II: Cyclin D and CDK inhibitors come of age. Cell 79: 573-582, 1994.

37. Scholzen T and Gerdes J: The Ki-67 protein: From the known and the unknown. J Cell Physiol 182: 311-322, 2000.

38. Gerdes J, Li L, Schlueter C, Duchrow M, Wohlenberg C, Gerlach C, Stahmer I, Kloth S, Brandt E and Flad HD: Immunobiochemical and molecular biologic characterization of the cell proliferation-associated nuclear antigen that is defined by monoclonal antibody Ki-67. Am J Pathol 138: 867-873, 1991

39. Ito $T$, Ando $H$, Suzuki T, Ogura T, Hotta K, Imamura $Y$, Yamaguchi $\mathrm{Y}$ and Handa $\mathrm{H}$ : Identification of a primary target of thalidomide teratogenicity. Science 327: 1345-1350, 2010.

40. Parman T, Wiley MJ and Wells PG: Free radical-mediated oxidative DNA damage in the mechanism of thalidomide teratogenicity. Nat Med 5: 582-585, 1999.

41. Donmez G, Sullu Y, Baris S, Yildiz L, Aydin O, Karagoz F and Kandemir B: Vascular endothelial growth factor (VEGF), matrix metalloproteinase-9 (MMP-9), and thrombospondin-1 (TSP-1) expression in urothelial carcinomas. Pathol Res Pract 205 854-857, 2009

42. Ozer G, Altinel M, Kocak B, Balci M, Altan A and Gonenc F: Potential value of soluble intercellular adhesion molecule-1 in the serum of patients with bladder cancer. Urol Int 70: 167-171, 2003.

43. Oliver FJ, de la Rubia G, Rolli V, Ruiz-Ruiz MC, de Murcia G and Murcia JM: Importance of poly(ADP-ribose) polymerase and its cleavage in apoptosis. Lesson from an uncleavable mutant. J Biol Chem 273: 33533-33539, 1998

44. Bochner BH, Cote RJ, Weidner N, Groshen S, Chen SC, Skinner DG and Nichols PW: Angiogenesis in bladder cancer: Relationship between microvessel density and tumor prognosis J Natl Cancer Inst 87: 1603-1612, 1995.

45. Nicolini A, Ferrari P, Masoni MC, Fini M, Pagani S, Giampietro O and Carpi A: Malnutrition, anorexia and cachexia in cance patients: A mini-review on pathogenesis and treatment. Biomed Pharmacother 67: 807-817, 2013 .
46. Höglund P, Eriksson T and Björkman S: A double-blind study of the sedative effects of the thalidomide enantiomers in humans. J Pharmacokinet Biopharm 26: 363-383, 1998.

47. Ridoux $\mathrm{O}$ and Drancourt M: Lack of in vitro antimicrosporidian activity of thalidomide. Antimicrob Agents Chemother 43 2305-2306, 1999.

48. Moreira AL, Wang J, Sarno EN and Kaplan G: Thalidomide protects mice against LPS-induced shock. Braz J Med Biol Res 30: 1199-1207, 1997.

49. Shannon EJ, Sandoval FG and Morales MJ: In vitro thalidomide does not interfere with the activation of complement by M. leprae. J Drugs Dermatol 10: 274-278, 2011.

50. Mall JW, Schwenk W, Philipp AW, Müller JM and Pollmann C: Thalidomide given intraperitoneally reduces the number of postoperative adhesions after large bowel resection in rabbits. Eur J Surg 168: 641-645, 2002.

51. D'Amato RJ, Loughnan MS, Flynn E and Folkman J: Thalidomide is an inhibitor of angiogenesis. Proc Natl Acad Sci USA 91: 4082-4085, 1994

52. Lentzsch S, LeBlanc R, Podar K, Davies F, Lin B, Hideshima T, Catley L, Stirling DI and Anderson KC: Immunomodulatory analogs of thalidomide inhibit growth of Hs Sultan cells and angiogenesis in vivo. Leukemia 17: 41-44, 2003.

53. Oz ES, Aydemir E and Fışkın K: DMSO exhibits similar cytotoxicity effects to thalidomide in mouse breast cancer cells. Oncol Lett 3: 927-929, 2012.

54. Eter N and Spitznas M: DMSO mimics inhibitory effect of thalidomide on choriocapillary endothelial cell proliferation in culture. Br J Ophthalmol 86: 1303-1305, 2002.

55. Loftsson T and Duchêne D: Cyclodextrins and their pharmaceutical applications. Int J Pharm 329: 1-11, 2007.

56. Kratz JM, Teixeira MR, Ferronato K, Teixeira HF, Koester LS and Simões CM: Preparation, characterization, and in vitro intestinal permeability evaluation of thalidomide-hydroxypropyl$\beta$-cyclodextrin complexes. AAPS PharmSciTech 13: 118-124, 2012.

57. Alvarez C, Calero J, Menéndez JC, Torrado S and Torrado JJ: Effects of hydroxypropyl-beta-cyclodextrin on the chemical stability and the aqueous solubility of thalidomide enantiomers. Pharmazie 63: 511-513, 2008 .

58. Kale R, Tayade P, Saraf M and Juvekar A: Molecular encapsulation of thalidomide with sulfobutyl ether-7 beta-cyclodextrin for immediate release property: Enhanced in vivo antitumor and antiangiogenesis efficacy in mice. Drug Dev Ind Pharm 34: 149-156, 2008

59. Stella VJ, Rao VM, Zannou EA and Zia V: Mechanisms of drug release from cyclodextrin complexes. Adv Drug Deliv Rev 36 : 3-16, 1999.

60. Kirsh EJ, Baunoch DA and Stadler WM: Expression of bcl-2 and bcl-X in bladder cancer. J Urol 159: 1348-1353, 1998.

61. Sedlakova O, Svastova E, Takacova M, Kopacek J, Pastorek J and Pastorekova S: Carbonic anhydrase IX, a hypoxia-induced catalytic component of the $\mathrm{pH}$ regulating machinery in tumors. Front Physiol 4: 400, 2014.

62. Chen MC, Lee CF, Huang WH and Chou TC: Magnolol suppresses hypoxia-induced angiogenesis via inhibition of HIF-1 $\alpha$ /VEGF signaling pathway in human bladder cancer cells. Biochem Pharmacol 85: 1278-1287, 2013.

63. Borst P: Cancer drug pan-resistance: Pumps, cancer stem cells, quiescence, epithelial to mesenchymal transition, blocked cell death pathways, persisters or what? Open Biol 2: 120066 , 2012.

64. Goss PE and Chambers AF: Does tumour dormancy offer a therapeutic target? Nat Rev Cancer 10: 871-877, 2010.

65. Podhorecka M, Halicka HD, Klimek P, Kowal $M$ and Dmoszynska A: Thalidomide induces phosphorylation of histone $\mathrm{H} 2 \mathrm{AX}$ and increases rate of apoptosis caused by fludarabine in malignant lymphocytes of chronic lymphocytic leukemia in short-term cell cultures. Leuk Res 33: 997-1000, 2009.

66. Yu J, Liu F, Sun Z, Sun M and Sun S: The enhancement of radiosensitivity in human esophageal carcinoma cells by thalidomide and its potential mechanism. Cancer Biother Radiopharm 26: 219-227, 2011.

67. Margulis V, Lotan Y and Shariat SF: Survivin: A promising biomarker for detection and prognosis of bladder cancer. World $\mathbf{J}$ Urol 26: 59-65, 2008.

68. Lai PC, Fang TC, Chiu TH and Huang YT: Overexpression of securin in human transitional cell carcinoma specimens. Tzu Chi Med J 22: 171-176, 2010. 
69. Jian W, Levitt JM, Lerner SP and Sonpavde G: The preclinical activity of lenalidomide in indolent urothelial carcinoma. Anticancer Res 34: 3383-3389, 2014.

70. Ren S, Xu C, Cui Z, Yu Y, Xu W, Wang F, Lu J, Wei M, Lu X, Gao X, et al: Oncogenic CUL4A determines the response to thalidomide treatment in prostate cancer. J Mol Med Berl 90: 1121-1132, 2012.

71. Lopez-Girona A, Mendy D, Ito T, Miller K, Gandhi AK, Kang J, Karasawa S, Carmel G, Jackson P, Abbasian M, et al: Cereblon is a direct protein target for immunomodulatory and antiproliferative activities of lenalidomide and pomalidomide. Leukemia 26 2326-2335, 2012.

72. Greenberg AJ, Walters DK, Kumar SK, Vincent Rajkumar S and Jelinek DF: Responsiveness of cytogenetically discrete human myeloma cell lines to lenalidomide: Lack of correlation with cereblon and interferon regulatory factor 4 expression levels. Eur J Haematol 91: 504-513, 2013.

73. Puskás LG, Fehér LZ, Vizler C, Ayaydin F, Rásó E, Molnár E, Magyary I, Kanizsai I, Gyuris M, Madácsi R, et al: Polyunsaturated fatty acids synergize with lipid droplet binding thalidomide analogs to induce oxidative stress in cancer cells. Lipids Health Dis 9: 56, 2010.

74. Lv P, Luo HS, Zhou XP, Xiao YJ, Paul SC, Si XM and Zhou YH: Reversal effect of thalidomide on established hepatic cirrhosis in rats via inhibition of nuclear factor-kappaB/inhibitor of nuclear factor-kappaB pathway. Arch Med Res 38: 15-27, 2007.
75. Piura B, Medina L, Rabinovich A, Dyomin V and Huleihel M: Thalidomide distinctly affected TNF- $\alpha$, IL- 6 and MMP secretion by an ovarian cancer cell line (SKOV-3) and primary ovarian cancer cells. Eur Cytokine Netw 24: 122-129, 2013.

76. Zhang S, Li M, Gu Y, Liu Z, Xu S, Cui Y and Sun B: Thalidomide influences growth and vasculogenic mimicry channel formation in melanoma. J Exp Clin Cancer Res 27: 60, 2008.

77. Kotoh T, Dhar DK, Masunaga R, Tabara H, Tachibana M, Kubota H, Kohno H and Nagasue N: Antiangiogenic therapy of human esophageal cancers with thalidomide in nude mice. Surgery 125: 536-544, 1999.

78. Sasano H and Suzuki T: Pathological evaluation of angiogenesis in human tumor. Biomed Pharmacother 59 (Suppl 2): S334-S336, 2005.

79. Gordon JN, Trebble TM, Ellis RD, Duncan HD, Johns T and Goggin PM: Thalidomide in the treatment of cancer cachexia: A randomised placebo controlled trial. Gut 54: 540-545, 2005.

80. Grover JK, Uppal G and Raina V: The adverse effects of thalidomide in relapsed and refractory patients of multiple myeloma. Ann Oncol 13: 1636-1640, 2002.

81. Zhu D, Corral LG, Fleming YW and Stein B: Immunomodulatory drugs Revlimid (lenalidomide) and CC-4047 induce apoptosis of both hematological and solid tumor cells through NK cell activation. Cancer Immunol Immunother 57: 1849-1859, 2008. 